\title{
The 'Cod-Multiple': Modes of Existence of Fish, Science and People
}

\author{
Heike Schwermer ${ }^{1,2, *}$, Alexandra M. Blöcker ${ }^{1}$, Christian Möllmann $^{1}$ and Martin Döring $^{3}$ \\ 1 Center for Earth System Research and Sustainability (CEN), Institute of Marine Ecosystem and \\ Fishery Science, University of Hamburg, 22767 Hamburg, Germany; \\ alexandra.bloecker@uni-hamburg.de (A.M.B.); christian.moellmann@uni-hamburg.de (C.M.) \\ 2 Center for Ocean and Society, Christian-Albrechts-University Kiel, 24118 Kiel, Germany \\ 3 Institute of Geography, University of Hamburg, 20146 Hamburg, Germany; doering@metaphorik.de \\ * Correspondence: heike.schwermer@ae.uni-kiel.de
}

check for updates

Citation: Schwermer, H.; Blöcker, A.M.; Möllmann, C.; Döring, M. The 'Cod-Multiple': Modes of Existence of Fish, Science and People.

Sustainability 2021, 13, 12229.

https://doi.org/10.3390/su132112229

Academic Editors: Raúl

Romero-Calcerrada, Javier Cabello,

Manuel Pacheco-Romero and

Koldo Trapaga Monchet

Received: 30 September 2021

Accepted: 2 November 2021

Published: 5 November 2021

Publisher's Note: MDPI stays neutral with regard to jurisdictional claims in published maps and institutional affiliations.

Copyright: (c) 2021 by the authors. Licensee MDPI, Basel, Switzerland. This article is an open access article distributed under the terms and conditions of the Creative Commons Attribution (CC BY) license (https:// creativecommons.org/licenses/by/ $4.0 /)$.

\begin{abstract}
Fish represent a politically regulated, scientifically researched, industrially processed, commercially marketed and socially contested living marine resource. Related to this, the incorporation of resource users and stakeholders into fisheries management is particularly important. Such involvement has recently improved in terms of frequency, but institutional frameworks often result in a lack of recognition and integration of the diverse 'knowledges' of stakeholders involved. Against this background, we aim to uncover the potentials of additional knowledge types for management purposes, paving the way toward a more collaborative management. We first conducted qualitative expert interviews with different stakeholder groups (e.g., commercial fisheries, eNGO and administration) to map various 'knowledges' about cod (Gadus morhua), a major resource species in the Western Baltic Sea to reveal the various experiences and epistemologies revolving around it. The second analytical step consisted of examining how these 'knowledges' structure, inform and often enter into conflict with perspectives on and assessments of fisheries management. Potentials were identified regarding enhanced stakeholder engagement in management processes that provide food for thought to seek change in sustainable management of fish stocks in the future. Our study is a pointer to the need to transform fisheries management in a more social and participatory way. We argue that sustainable natural resource management cannot be designed solely by integrating more 'knowledges' (knowledge sharing) but requires the creation of social contexts and institutions with stakeholder empowerment at the local level (power sharing) to sustainably manage natural resources such as commercially importance fish stocks.
\end{abstract}

Keywords: Baltic Sea; fisheries management; cod; stakeholder participation; interviews; knowledge types; qualitative content analysis; co-management

\section{Introduction}

Fish is a living marine resource that is politically regulated (management), scientifically researched (advice to inform management), industrially processed and commercially marketed (sales to restaurants, supermarkets and auctions) but also socially controversial (resource and spatial conflicts). The interaction of interest groups and resource users (referred to as stakeholders), their institutional rationales and the respective 'knowledges' (encompassing the multiplicity of various knowledge types) produced about and revolving a fish species have developed into existing management approaches and regimes. These, in turn, are constantly shaping and reshaping the relationship between fishing communities, fishing industry, scientists, institutional representatives, political stakeholders and regulating bodies. More importantly though, they are in many cases based on a normative and enacted understanding of what fish actually is. However, there is not only one but rather various framings of 'knowledges' and representations of fish, turning it into a messy multiplicity. 
This messy multiplicity of the resource fish is in many cases reduced to the rationale of natural resource governance aiming at regulating human behavior [1]. Embodied in laws, assessments, interventions and prohibitions, the regulation of the removal of fish is based on the basic presupposition that human actions negatively affect nature [2]. There is, however, the epistemological problem that fish is not directly or fully graspable for humans. Turning it into a manageable and governable entity requires acts of classification as well as processes of justification. In most cases, these are relegated to science defining and legitimating all sorts of interventions and regulations [3]. For this to be performed, specific scientific techniques and procedures are used to assess, organize, translate and define what fish actually is [4]. Once measurements, quantifications and model runs have been gathered, the fish is re-assembled and reified as a somewhat homogeneous object [5]. Thereby, fish is reduced to a powerful scientific mode of existence that legitimates the creation of concrete management [3].

Such interventions are not uncontroversial, which has recently led to reshaping the research agenda in marine and fisheries management. Traditionally seen, people have been framed as the key drivers for negative impacts representing their activities as one of the most pressing challenges for the sea and its fish stocks [2]. This perspective underwent change partially due the increasing role of external environmental stressors on fish populations [6]. Examples include the expected implications of climate change, while the growing relevance of communities, interest groups and resource users in developing solutions has also continuously been acknowledged [6]. Hence, the concepts of environmental stewardship, citizenship [7,8] or marine citizenship [9] have been taken up. Here, emphasis has been placed on the relevance of non-scientific ocean knowledge in re-assessing scientific approaches while at the same time enlarging the scope of management interventions [10].

For society, communities [11] or social stakeholders to be conceived as an important part for developing marine management options, a relational approach has been considered to be of particular relevance. Simply put, such an approach investigates the various ways through which people and the sea relate to each other which is for example emphasized in the context of co-designing options for the exploitation of natural resources [12]. This understanding reveals and provides insight into the multiplicity of perspectives through which the various dimensions of the multifaceted 'relationality' between human beings and the sea could be studied. Consequently, methodological, theoretical and practical approaches have been explored. These, for example, focused the attention on (i) the social dimensions of management options [13-15], (ii) the perception of different stakeholder groups [16,17] and (iii) the framing of fishers with regard to management structures and measures bearing an impact on their everyday lives [18]. Moreover, the research on ocean literacy characterizes approaches in the area of local ocean knowledge disclosing the aspect that these dimensions could considerably contribute to ocean citizenship and stewardship, including other interest groups or resource users such as fishers [19].

Besides these more general aspects addressed, additional specific aspects such as varying epistemologies as a barrier for integrative research have only recently gathered attention [20]. The co-construction and implementation of differing 'knowledges' in the context of management have been defined as an important task [21], although approaches of this kind appear to be still at the beginning. Based on the insight, that various disciplines and social groups produce and hold differently structured 'knowledges' about fish and fisheries [22,23], relatively new research has focused on understanding what presuppositions underpin this knowledge, how this knowledge is produced and in what ways it is conceived to be applicable in the context of governance and management [20]. Discussions of robustness, adequacy and legitimacy accompany the discussion about nonscientific 'knowledges'. However, objective scientific knowledge also supposedly came under scrutiny [24]. This critical perspective on the epistemilogicization has fueled coconstructive management approaches [25], among which the co-development of qualitative models [26] or mental mapping procedures [17] represent more recent approaches. 
The problem with co-management approaches including differing 'knowledges' and procedures lies in the fact that they were regarded as a panacea for solving problematic aspects of governance and sustainable management [27]. The acknowledgement and incorporation of local 'knowledges' is, however, still thwarted by the sometimes underlying rationale of evidence-based management approaches, the extension of scientific epistemologies and the maintenance of their implicit objectivist rationales (see for an early assessment [28]). A critical investigation of this dimension is still missing in many cases and touches upon the prevailing assumption that social life is determined by deep social structures which underlie and rationally regulate " $[\ldots]$ the seemingly chaotic world of [the] social [ ... ]" ([29], p. 382). This understanding was challenged by approaches that frame the social as an assemblage or formation as based on social practice. These approaches reckon practices as processes that assemble or network-in our case-fish, fishers, the fishing industry, scientists, politicians, etc., together. Focusing on the social to provide better management options thus promotes an important shift from the why (deep cause) of social formations and framings to the how (surface processes). In brief, the focus of research is taken away from uncovering the deep and governing structures toward a more dynamic understanding in terms of social networks or assemblages. In doing so, it could pave the way toward a more inclusive and symmetric way of managing fish [30].

For this to be achieved, a critical inspection of the scientifically informed discourses revolving around fish is necessary. Such an investigation of the problem framing puts emphasis on the messiness [31] of fish discourses. This would mean that one has to reveal the many human practices and 'knowledges' that create and re-create fish [32]. These processes indicate how fish is framed by various stakeholders and how fish, humans and science are woven together in specific ways and contexts [33,34]. Such an understanding strongly contrasts with current approaches in which fish is framed in specific-mainly scientific-ways and becomes a governable and manageable object.

These procedures and ways of conceptualizing fish often obtain a truth-like social status which is questionable. There is no independent fish from the world 'out there', but only socially embedded theories and models constructed about it. Hence, fishers, scientists or politicians do not describe the world from a neutral point or perspective, they rather engage with it specifically and thereby shape it. Such a shift from decontextualized thinking (epistemology) to a situated engagement (ontology) and generation of knowledge represents a challenging step. This affects fishing practice and introduces new regimes of control. What becomes apparent is the fact that this construction of fish is stabilized and networked into a regime by "[ ... ] tying fish with fishermen, echo integrators, log books, legislation, computers, bureaucracies, mathematical formulas, and surveillance procedures" ([35] p. 239). The same holds true for stock assessment models: "they move fish from the water [ ... ] to the paper of reports and policy" ([36] p. 1017), framing them as swimming inventories of future biomass and economic value [37]. Clearly, decontextualized scientific or political abstractions of fish contrast contextualized human-fish relations [38]. The question consequently remains which knowledge type has to be considered as relevant and for what reason?

Western Baltic (WB) cod (Gadus morhua) is one of these fish (stocks) that is politically regulated, scientifically researched, commercially marketed and socially contested. Because of its depleted stock status, this fish stock is presently of special concern and debate among fishers, scientists, environmental conservationists and politicians [39]. WB cod is ecologically important as a top-predator in local food web dynamics [40] but is also an economic asset (e.g., for jobs or tourist facilities such as fish restaurants) for coastal areas in Germany [41]. Moreover, from a cultural point of view, cod has a special status at the WB coast because commercial fisheries here have a long tradition and culture that is anchored in and strongly attributed to cod (a description of stock assessment details can be found in Supplementary Material). The WB cod case is a typical example of a conflict over the state and the right management measures to recover a depleted fish stock while safeguarding the social system depending on it not only in the EU. At the same time, it becomes apparent 
that there is not one but different framings, 'knowledges' and representations for WB cod, making it a confusing diversity or, as we call it, a 'cod multiple' [12,31,42].

Deconstruction, the critical analysis of discourse in terms of knowledge orderings and the insight that humans are enmeshed [43] with the world, opened up a perspective in which the complexities of the social revolving around fish can come into view. Understanding fish, humans and science as entangled [44], we now take the turn to investigate the forms of 'knowledges' revolving around WB cod and its current management. 'Knowledges' here encompasses multiple forms of 'knowledges', which are informed by different rationales. Examples include evidence-based knowledge (e.g., collected by established surveys to determine the distribution of fish stocks) and tacit knowledge (knowledge generated through job-related interaction with the ecosystem, i.e., fishers' ecological knowledge). We here follow the diverse 'knowledges' held by various groups, meaning commercial fisheries, science or environmental non-governmental organizations (eNGOs) with the aim to reveal its complexities and multiplicities. Our analysis eventually aims to understand how ignoring specific knowledge types potentially causes conflicts in fisheries management. We propose how different 'knowledges' can be integrated to regain the trust of stakeholders in the decision-making process.

\section{Materials and Methods}

To empirically and qualitatively study the 'knowledges' revolving around the management of WB cod, we applied an interconnected sequence of methodological steps (Figure 1, consisting of data collection, coding and data analysis). At its core, this is based on conducting and analyzing expert interviews. With this approach, we were able to uncover the diverse 'knowledges' revolving around WB cod as well as its local, national and supranational background [45].

\subsection{Data Collection}

We initially conducted a systematic in-depth reading and content-oriented document analysis of a wide variety of written sources comprising the news coverage in German newspapers of the last 10 years, as well as recent political and governmental documents (e.g., Common Fisheries Policy) [46] (Figure 1A). In addition, we analyzed published opinions, reports or written statements of the various stakeholder groups regarding the issue of WB cod, its fisheries, and the problems surrounding it [47]. In addition, we studied project reports as well as scientific publications to gather various perspectives on the multiple issues associated with the cod resource [48-51]. This first step helped us to reconstruct and understand the developments, disputes and discourses pervading the socalled 'cod-controversy' persisting between different groups involved in the management.

Based on the media analysis (Figure 1A), which served as a thematic background analysis on cod fisheries in the Western Baltic Sea, an interview guide was developed and tested during two sample interviews [52] (Figure 1B). A previous scientific analysis of German newspaper articles on WBS fisheries revealed a high media presence (i.e., absolute frequency) of the topics ecology, management, economy and communication within the news coverage. These were selected as thematic building blocks of the interview guide (Table 1).

The interview guide included questions about the current condition of WB cod, elaborating on causes for this situation and discussing possible solutions in terms of various national and EU-wide management options (Table 1). Economic as well as social impacts regarding WB cod fisheries and its management were also addressed (Table 1). At the end of each interview, all interviewees were given the opportunity to reflect on the future development of WB cod within the coming years. Likewise, space was provided for further aspects not addressed in the interview (Table 1; all interview questions are listed in detail in the Supplementary Material Table S1). 

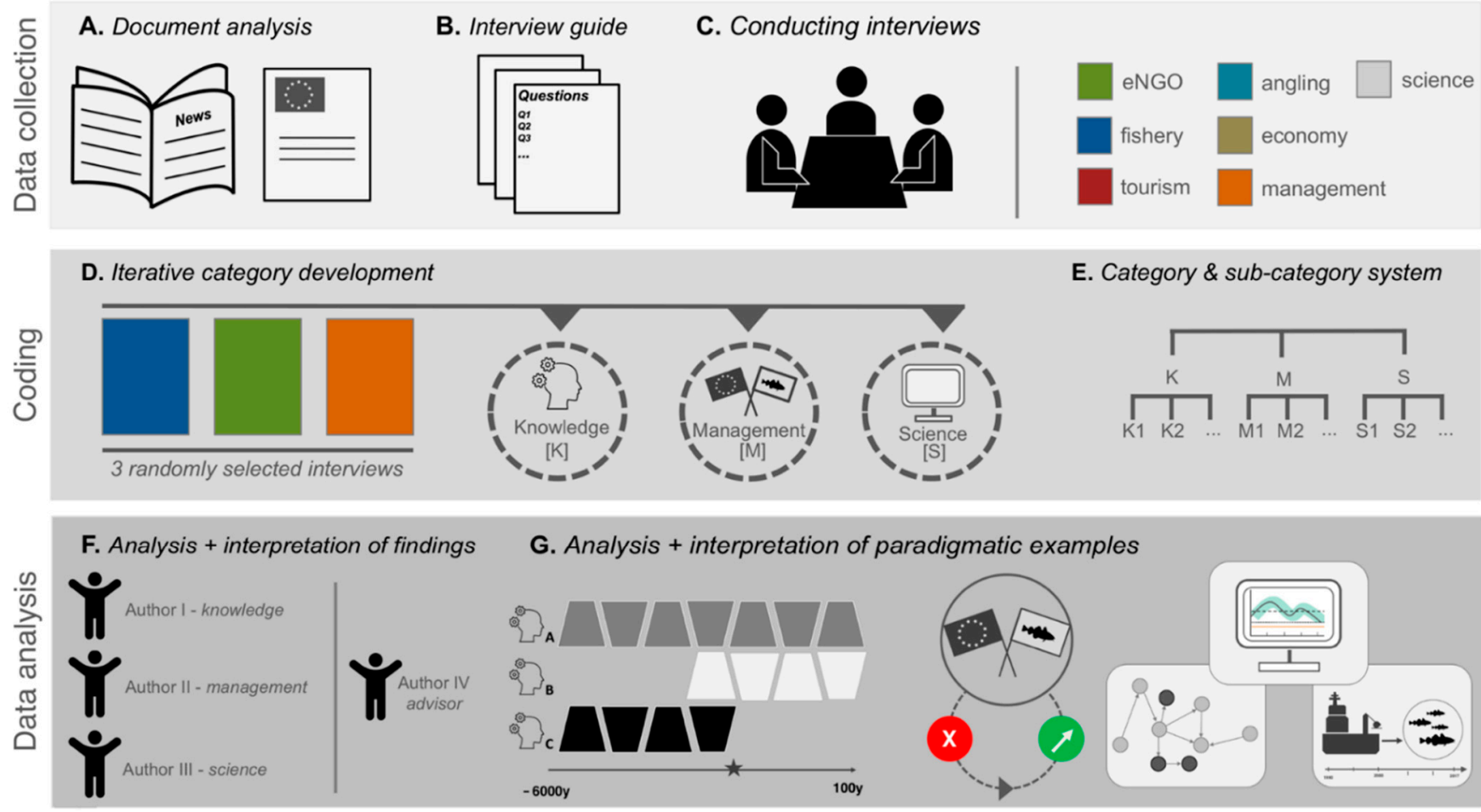

Figure 1. Illustration of the applied methodological procedure including data collection, coding and data analysis. (A) A systematic in-depth reading and content analysis of a variety of different written sources was conducted, including news coverage in newspaper databases as well as political and governmental documents. (B) An interview guide was developed including questions related to ecology, management and economy of WB cod and the communication between stakeholders. (C) Each interviewee was provided with the interview guide a week in advance and was walked through the guide at the beginning of the interview. All interviews were carried out by two to four interviewers and have been transcribed verbatim. (D) To start the analysis, three interviews of different stakeholder groups were separately read and discussed for general content, key issues and unexpected, emerged topics. Interview calibration confirmed a set of three main themes: 'knowledge' of WB cod, role of 'science' in the disputes, and perceptions and critiques of the EU fisheries management. (E) Categories were applied to all interviews resulting in a category and subcategory system. (F) After the completed interview coding, each of the three categories was assigned to one author conducting an in-depth analysis. (G) The data provide a deep insight into the diversity of knowledge types in time and structure, perceptions and descriptions of fisheries management, and scientific use of models and their underlying data collection form.

Table 1. Description of thematic blocks addressed during the interviews.

\begin{tabular}{cc}
\hline Thematic Block & Description \\
Ecology & $\begin{array}{c}\text { Understanding and knowledge of the ecology of the Western Baltic Sea in general and of } \\
\text { WB cod in particular; identification as well as description of abiotic and biotic } \\
\text { factors influencing the system }\end{array}$ \\
Management & $\begin{array}{c}\text { Understanding of European fisheries management and description of different measures; } \\
\text { outlining the criticisms of fisheries management in general and description of the } \\
\text { effectiveness as well as consequences of different measures }\end{array}$ \\
Economy & $\begin{array}{r}\text { Description of economic links concerning the commercial fishery as well as economic effects } \\
\text { of management measures on the regions of Schleswig-Holstein and } \\
\text { Mecklenburg-Vorpommern }\end{array}$ \\
Communication & $\begin{array}{c}\text { Perception of communication and description of the current involvement of different } \\
\text { groups in fisheries management and ideas for improving the current situation }\end{array}$ \\
\hline
\end{tabular}


Using purpose sampling strategies, relevant stakeholders were selected on the basis of (i) the first authors knowledge, (ii) a desktop study of relevant institutions and (iii) the aforementioned analysis of German newspaper articles [53,54]. Interviewees were selected using two key criteria: stakeholders needed to (i) be associated with a German institution dealing with commercial fisheries by either their job or honorary position and to (ii) have been involved in the WB cod fisheries for more than 5 years. The latter criterion was chosen as a reference point to ensure that interviewees had established themselves in their professional position (job, volunteer) and are familiar with the subject of WB cod fisheries over a relevant period of time. All interviewees selected act as managers or working group leaders (of their associated institution), which guaranteed their content-related immersion into as well as their expertise about the topic of WB cod fisheries (Table 2). Furthermore, interviewees were chosen with regard to their role in the discourse revolving around WB cod, their political, administrative or professional function while they differed in terms of gender and educational level representing a great variety of stakeholders involved in the disputes.

Table 2. Stakeholders from seven different groups were interviewed on the topic of ecology, EU fisheries management and economy of Western Baltic cod fisheries (eNGO = environmental non-governmental organization).

\begin{tabular}{ccc}
\hline Stakeholder Group & Description & $\%$ \\
\hline Fisheries & $\begin{array}{c}\text { Representatives of the German commercial } \\
\text { fisheries and head of the fishery cooperative, } \\
\text { i.e., political representation of the fisheries and } \\
\text { communication of management measures to } \\
\text { the fishers }\end{array}$ & 2 \\
Economy & $\begin{array}{c}\text { Representatives of the German fishing industry } \\
\text { with focus on consumer information } \\
\text { Officials focusing on catch quotas and fisheries } \\
\text { management at federal and state level } \\
\text { Representative working on marine } \\
\text { conservation (with a focus, e.g., on catch } \\
\text { quotas and environmental education) on } \\
\text { international, national and regional level } \\
\text { Representative of the German recreational } \\
\text { fisheries with, e.g., tasks of communication of } \\
\text { political regulations as well as nature } \\
\text { conservation projects }\end{array}$ & 2 \\
Angling & $\begin{array}{c}\text { Researchers with focus on fish stock } \\
\text { Scientists }\end{array}$ & 3 \\
& $\begin{array}{c}\text { assessment, Baltic cod ecology and recreational } \\
\text { fisheries }\end{array}$ & 3 \\
Tourism & $\begin{array}{l}\text { Association members with focus on the } \\
\text { promotion of angling tourism at regional level }\end{array}$ & 1 \\
\hline
\end{tabular}

In total, we selected 13 stakeholders of seven different groups comprising commercial and recreational fisheries, eNGO, tourism, economy, administration and science (Table 2, Figure 1C). To allow for content-related preparation, the interview guide was provided to the interviewees one week in advance. Before each interview, information on the respective interviewee (institution, person) was gathered to gain background knowledge and to prepare interviewers. To maintain a good interview atmosphere, interviews were conducted at places chosen by the interviewees [55] and started by asking questions about the individual expertise of the interviewee. All interviews were carried out by a minimum of two, maximum of four interviewers (period: 2 November 2017-18 May 2018), lasted between $45 \mathrm{~min}$ and $2 \mathrm{~h}$ and were transcribed verbatim. 


\subsection{Data Analysis}

To zoom in on the analysis, we chose a qualitative approach including a re-screening of relevant documents to begin with [56]. This perspective held the potential to disclose the somewhat unconscious patterns of interpretation and meanings permeating the varying perceptions and assessments of the cod problem at work in the disputes [57].

In a first analytical round, three interviews of different stakeholder groups were separately read and analyzed by three authors (HS, AMB, MD) of this paper. The selected interviews were discussed in terms of general content, key issues and unexpected topics that emerged during the provisional analysis (Figure 1D). The outcome led to the decision to analyze all interviews from a grounded point of view $[58,59]$. This approach offers the opportunity to inductively develop analytical categories and holds the potential to avoid as far as possible preconceptions or circular reasoning based as on unarticulated or unconscious presuppositions by the analyst. Hence, once central themes or topics emerged, segments of the interviews transcribed were individually grouped in preliminary analytical categories. These bottom-up categories were discussed in a step-by-step approach among three authors (HS, AMB and MD) to assess their general meaning, analytical plausibility and empirical relevance for the study. This procedure contributed to calibrating the coding of all interviews resulting in a corroborated set of three main topics of interest [60]: 'knowledges' about WB cod in terms of ecology and economy, the role of science in the disputes and the perception and criticism of respective management approaches (e.g., catch quotas) (Figure 1E). For further coding and categorization, simple tables were used in which text segments, their interpretation with a focus on the language used, the explanatory ascription to a category and the interview reference plus line numbers of the respective transcripts were entered. All categories were constantly discussed between the three authors to secure intercoder reliability.

Once the three endpoints, knowledge, science and management, were analytically established, each of these categories was assigned to one of the three authors performing an in-depth analysis of one of these overarching categories (Figure 1F). Respective subcategories were defined using an inductive approach which means that main categories were defined beforehand and corresponding subcategories were developed during subsequent analyses from the material [61]. Subcategories were developed step by step, i.e., general units were grouped during reading and, if possible, categorized in the process of re-reading the selected segments (see Supplementary Material Table S2a,b, S3 and S4). All developed subcategories provide a meaningful and empirically sound analysis of the three categories of knowledge, science and management. As a result, the analysis provided a fine-grained insight into the multifaceted and dynamic processes of social meaning making with regard to the structure of controversies revolving around the current fisheries management of WB cod.

\section{Results}

Overall, our comprehensive analysis of the interviews revealed a large number of different subcategories, which were assigned to the three main categories knowledge, science and management (see Supplementary Material Tables S2a,b, S3 and S4 for a detailed description of all subcategories). These represent to a large extent the complexity of the data gathered and give a deep insight into the meaning structure of the topic (Figure 2). Of particular importance is the description and analysis of the WB cod stock (further referred to as cod), the perception and attributed role of science, and the evaluation of current management measures, with specific attention to the prevailing problems and its potential for improvement (Figure 2). In the following section, selected interview excerpts are translated from German (interview language) into English. 

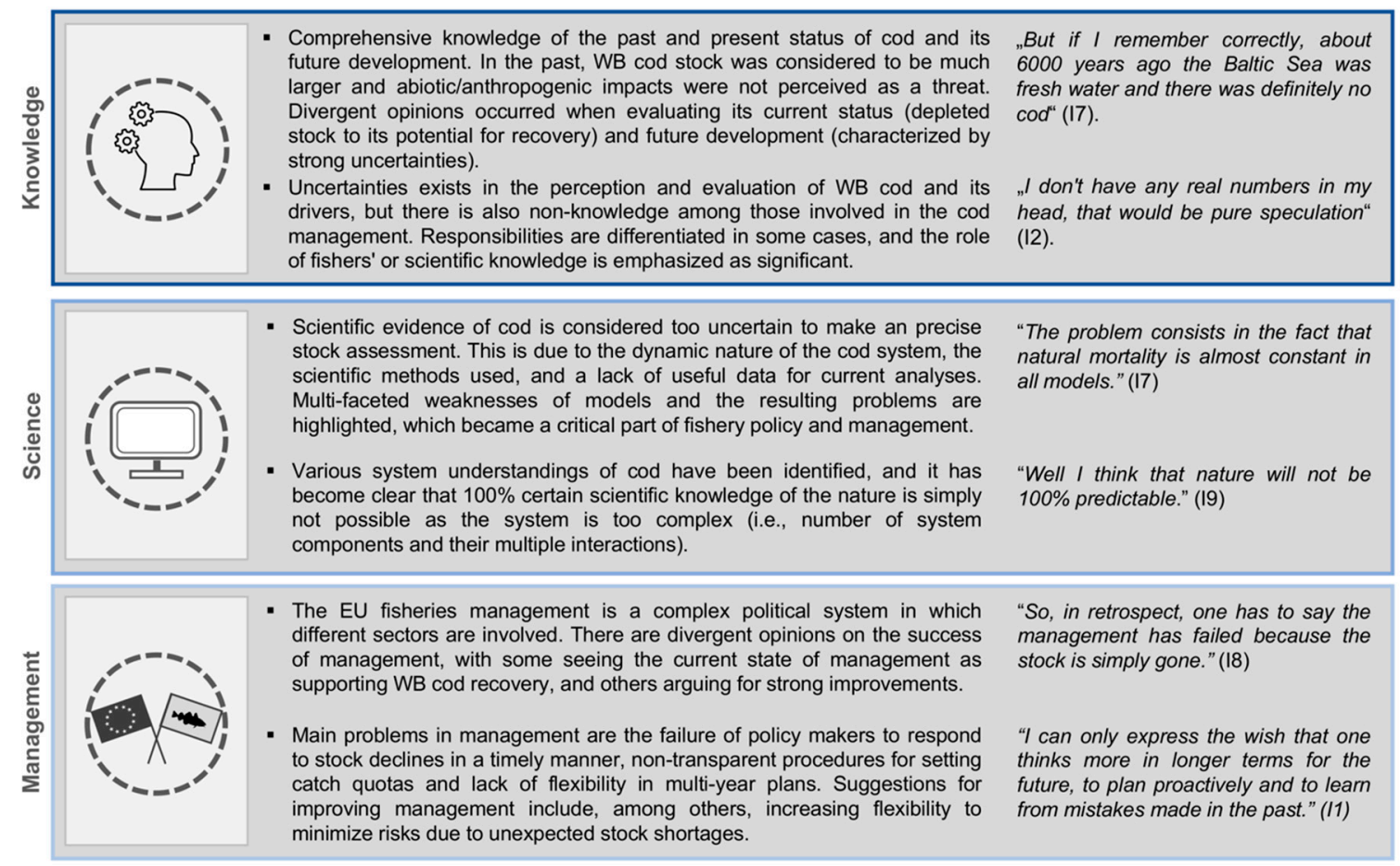

Figure 2. Overview of the results deriving from the comprehensive analysis. The three main categories of knowledge, science and management are expressed according to selected subcategories, focusing on the complexity of cod, its fisheries and management. Of particular relevance are the description cod in the past, present and future, the perception and attributed role of science, and the evaluation of current management measures, its problems and potential for improvement. The description of each category is complemented by meaningful quotes from the interviews conducted.

\subsection{Knowledge}

In general, the category knowledge includes all content that can be traced back to the knowledge of the interviewees and is not ostensibly related to the categories management or science. From the text, we have developed subcategories that either have a local reference (e.g., local knowledge) or focus on a temporal component (e.g., historical and future knowledge), and also represent situated knowledge of individual stakeholders in the system such as fishers or anglers (for a detailed description of assigned subcategories see Supplementary Material Table S2a,b). To gain a detailed insight into the subject of cod, we further focus explicitly on the stock in different time periods. Based on our interview analysis, it became apparent that the general assessment of the cod stock strongly relies on a threefold distinction made between historical and future knowledge and the description of its current state. The consideration of these three dimensions with their implicated temporal dimensions refers to the importance of a detailed presentation analyzing the various knowledge types separately and in a differentiated manner.

\subsubsection{What We Know-The Past, Present and Future Cod Stock Status under Review \\ 1. Historical knowledge}

In both, their perception and description of the past state of the cod stock, interviewees not only refer to different time periods but also explicitly to stock characteristics such as biomass or recruitment (i.e., individuals added to the exploited component of a stock). In this regard, we detected a wide range of reference periods from only two years up to several thousand years in the past as well as different temporalities (e.g., biological, institutional temporality).

The greatest reference time of 6000 years was used to express that "the Baltic Sea was roughly fresh water and there was certainly no cod there" (I7). By using a biological temporality, the interviewee reflects an evolutionary change of the Baltic Sea ecosystem 
and expresses his knowledge regarding the cod's salinity preference. The interviewee is not concerned with describing the size of the stock or its individual characteristics such as recruitment, rather he wants to show that cod was not always present in this ecosystem due to its physiological characteristics. In addition, using a biological temporality, there is a description of the past size of cod during spawning, which "used to spawn at $70 \mathrm{~cm}$, $70,80 \mathrm{~cm}$." (I10). Reference is made to the change in spawning size in general, as well as to the exact length during past spawning.

However, the interviewees do not only use the physiological characteristics of cod to describe its past condition. Rather, as the following example shows, they refer to its occurrence as a food source for the community, which is here placed in relation to its stock size.

"People always like to talk about the breadwinning fish of the region. Well, there were times when you probably got a choking feeling when there was cod again, people would say, or children would say: Not cod again. And there was always cod, because it was there in masses." (I10)

The use of a social temporality very much reflects the interviewees' knowledge regarding past cod biomasses, which were so high that cod metaphorically tended to be equated with "a choking feeling" (I10).

However, if the past relates to a shorter reference period such as a few "decades" or even fewer years, interviewees primarily refer to an institutional temporality, meaning reference periods directly linked, in our case, to the fisheries management. When interviewees describe past cod stock conditions to a period such as "the last decades" (I10), this is performed by using the exact reference value at which time the stock had both high biomass values and "very high recruitment years" (I2). This institutional temporality is used by the interviewees to show a contrasting state of the cod stock, compared to the current one, from a management perspective. The same temporality applies when interviewees consider shorter time references such as "the last years" (I8) to make direct reference to recruitment in 2015 and 2016 in particular, or to define "recruitment has been poor [in general] the last few years" (I8). More specifically, the 2016 recruitment was an "exceptionally strong cohort" (I5) and a "reason for hope" (I11), while the "[20] 15 was even historically the worst ever" (I13). However, there are also "people who doubt that the [20] 15 really failed" (I7).

Both the ecological conditions (biological temporality) such as the state of the Baltic Sea and anthropogenic influences such as fishing pressure or nutrient inputs are used by the interviewees to express historical knowledge about cod. One interviewee even refers to "the highest cod stocks" (I9) at a time when phosphorus inputs into the Baltic Sea were among the highest. Interestingly, nutrient input is not described as a limiting factor for marine fish species. Rather, the increased high nutrient levels lead to increased fish biomasses.

\section{Knowledge on present cod stock}

However, in order to present a comprehensive understanding regarding the assessment of the cod stock, the perception and description of the current status are also key, here focusing on the biological and tacit knowledge only. Diverging opinions across interviewees are present, ranging on a continuum from "worried" (I12) to strong assumptions of a rapid recovery of the stock. In terms of very low stock level, the cod stock is described as currently "close to collapse" (I8), indicating very low recruitment as well as low biomass values. The latter is particularly evident in the curves after which the stock has "gone very, very much into the cellar" (I10). The following example also uses this metaphorical representation "in the cellar" to highlight the very poor stock conditions of cod.

"Overall, this is a difficult water for marine species because of the low salt content, and in the case of cod it is impossible because the stock is simply in the cellar, and it always takes them two or three years, if a good recruitment is achieved, for them to grow in biomass." (I8)

Furthermore, stock condition is strongly distinguished from a former "golden age" (I13), which symbolically refers to past positive periods with higher biomasses and strong 
recruitment. The current situation is that the stock "is basically no longer economically exploitable. It has reached one of the lowest spawning biomasses we have ever had [and] [i]s deep in the red" (I4). Not only in this example is the color red used to symbolized the very poor condition of the stock. In addition, "[t]he size distribution tends towards smaller cod" (I13), which again indicates that the overall stock is currently not in a good state. Some interviewees go even further by saying that the "existence is definitely at risk" (I8), while framings on the present stock status vary. A contrasting positive assessment is generally linked to the 2016 recruitment leading to a predicted stock recovery.

"So, we were very, very happy in spring when we got the first information about the evaluation from 2016, that this is going into the right direction." (I13)

Interviewees also describe the development toward the current state as "pure luck" (I4) and again refer to the uncertain predictability of the recruitment and the stock in general. However, cod is also characterized by its biological properties which allows assumptions to be made regarding its future development. This includes a description of as a migratory fish species meaning its non-stationary habit and ability to move over long distances, resulting in mixing with the eastern stock.

"The cod is not necessarily stationary, it is also always looking for the same structures, which is why it is important to say that reefs, for example, need to be generally protected. But then the cod will migrate and at some point, it will be somewhere else, it can migrate for many kilometers." (I12)

The broad adaptability of the cod stock, as to different salinity levels, is seen by interviewees as an advantage with regard to future changes in abiotic factors, i.e., there is no "risk of losing this stock or the species" (I7).

A closer look at the past of WB cod described by the interviewees highlights that the stock has not only undergone an evolutionary change according to its size during spawning, but that in the past, the stock was so large that even the community experienced vomiting stimuli. In addition, special mentioning should be made of the cod's recruitment, which was one of the worst in the time series in 2015, while recruitment in 2016 was so strong that it had the "potential to at least extremely accelerate the stock build-up" (I11). A strongly divergent opinion emerged when looking at the current state of the cod. It is "pure luck" (I4) that there was such a strong new cohort, and the current development is rather a cause for concern and the stock "close of collapse" (I8). Furthermore, consideration of the current status already gives indications of its future development-for example, a development toward a smaller cod population is assumed (I13).

\section{Future knowledge}

Considering the future of $\mathrm{WB}$ cod, different time horizons were also used by interviewees compared to historical knowledge. It is important to note, however, that estimates are usually not made for exact years.

According to one interviewees and his/her use of a biological temporality, "[cod] will never die out" (I8), only if "no more salt water comes in at all and the Baltic Sea becomes a freshwater lake, then it will no longer be there" (I7). Here, again, reference is made to the state of the Baltic Sea ecosystem and a possible extinction of cod in view of its preference for saltwater. The following example also picks up on the biological endangerment of the stock but, compared to the other statements, gives a clear statement about the time reference:

"And whether this will be the case again in 5 or 6000 years, who knows? But with the manageable horizon of 100 years, which we always roughly take, I don't really have the worry that the cod will become extinct biologically." (I7)

Furthermore, in an attempt to make a statement about a possible future development of the stock, explicit reference is made to the strong recruitment in 2016 (institutional temporality).

"If it goes somewhere, it's more likely to go up, how much this step actually goes up now, through the 2016 cohort, you have to see. But it's not like they say it's 
rock bottom and we don't see any light at the end of the tunnel at all, but there are actually gateways that somehow seem to be opening up right now" (I5).

The images "light at the end of the tunnel" and "gateway" strongly imply a dynamic development in the context of stock condition. A clearly positive development of the stock is predicted but also an indefinite time reference, meaning that it is not foreseeable when the "tunnel" will be crossed. "But the perspective [regarding the spawning stock biomass] is at least good" (I4). This is contrasted with prognoses that do not assume that "this good recruitment will actually occur" (I8). It can thus be seen that the perception of this development diverges among interviewees, giving a clear indication of existing uncertainties of future stock conditions.

There is also considerable uncertainty about the factors affecting the cod stock such as temperature or North Sea inflow events (biological temporality) determining the perception of an uncertain stock development (institutional temporality).

"And that is the great danger, so I see the greatest risks in these factors. They can go in all directions. It is possible that the stock recovers drastically and then there is too little food, which has an impact on other habitats. But it is also possible that it will collapse completely again. And we cannot foresee this." (I1)

The future perspective on stock conditions is characterized by uncertainties strongly reflected by the use of mostly no time indications. All interviewees assume that WB cod will "never die out" (I8), yet the perception of its future development is characterized by diverging opinions. While on the one hand "light [is seen] at the end of the tunnel" (I5), on the other hand, it is clear to the interviewees that there is no good recruitment in sight.

Stakeholders not only have a comprehensive knowledge of the cod's past and present condition but also an anticipation of its future. Historically, cod was conceived as much larger in terms of its biomass, and there was mostly a consensus on its good historical status among interviewees. Abiotic or anthropogenic impacts were not perceived as posing a threat to the state of the cod, and even from a social perspective, cod was highly abundant, as its status as a valuable food source was not comparable to today. Diverging opinions emerge when looking at the current stock status, ranging from a depleted stock to its potential for recovery. Above all, the evaluation of recruitment plays a significant role on all time levels. The 2016 cohort is under special scrutiny and determines the opinions of the interviewees not only about the present stock state but also about its future development. The latter is most strongly characterized by uncertainties and shows a high variability in the perception and assessment of the interviewees.

\subsubsection{What We Do Not Know-Exploring the Diversity between Uncertainties and Non-Knowledge}

The interviewees' knowledge is reflected in many different types, ranging from local and tacit knowledge to biological or economic knowledge. However, our comprehensive analysis of the interviews also shows that the perceptions and descriptions of cod and its surrounding factors are subject to uncertainties and even explicit non-knowledge (see Supplementary Material, Table S2a for a detailed description).

The following quote serves as a very appropriate introduction into the discourse of diversity between uncertainty and non-knowledge, clearly demonstrating the existence of knowledge constraints in the context of WB cod, including various impacts on the stock such as abiotic and biotic variables.

"What we might have to say about this is that, of course-interestingly, cod that is economically so important, but actually we have the least information if we are honest." (I1)

The interviewee is aware of great economic importance of cod but also states that limited information is available about it in general. This "least information" suggests not only existing uncertainties but also non-knowledge regarding WB cod. 
When it comes to assessing the cod stock, there are strong uncertainties or even non-knowledge associated with the 2015 recruitment. There is knowledge that "except that the 2015 cohort has failed for inexplicable reasons and the 2016 cohort is one of the strongest since records began for the Western stock" (I7). However, there is uncertainty about the reasons that explain this phenomenon, as well as a lack of knowledge about "what age group is there now and why are they small and is this still an older age group" (I1). Uncertainty in the assessment of stock size also arises in relation to the gadoid outburst and high nutrient inputs that occurred in this context (biological temporality). The question is not if/whether high cod biomasses occurred but rather "[ . . ], if this has been discussed before [ ... ], whether that was also nutrient driven" (I7).

However, it becomes apparent that uncertainties and non-knowledge are in many cases legitimized by the profession carried out by the interviewees. Interestingly, this legitimacy is derived exclusively at the level of stakeholders from fisheries and science. Interviewees describe themselves as "not doing any scientific work" (I3), not being "a biological expert on Baltic cod" (I7) or not being a "climate scientist" (I13). In other examples, interviewees explicitly point out that this is "a question that has to be answered by practitioners" (I2) or "[s]cience has described it" (I7). The last-mentioned example goes back to the description and evaluation of the 2015 cohort. The interviewee describes that "[a]ctually, there is nothing special going on, except that the 2015 cohort failed for some inexplicable reason and the 2016 cohort is one of the strongest since records began for the Western stock." (I7). Further, non-knowledge is pointed out by stating "Why this is so I don't know, but it is." This statement is ultimately legitimized by "[s]cience has described it." (I7).

The important role that fishers' knowledge plays in the context of legitimizing uncertainty or non-knowledge of other stakeholders is again brought strongly into perspective by the following, very illustrative example. While the interviewee does not want to comment on the cormorant's influence on the cod stock, he/she refers directly to "practitioners, [...], who are out there every day and say yes, I see the cormorants throwing themselves at our young cod and pulling them out of the water by the kilo, no, by the ton" (I2). The acknowledgment of fishers' knowledge, arising from the direct interaction of fishers with the ecosystem itself ("who are out there every day"), is once again highlighted here. This is further emphasized by the question of the cod's economic role in commercial fisheries. Another interviewee clearly points out that "[he/she is] not a professional fisher, it is difficult to judge" (I10).

In the following section, we would like to explicitly address the uncertainties and lack of knowledge about parameters affecting WB cod. Climate change is one example influencing stock dynamics, where its legitimacy varies from "I am a businessman and have little knowledge of climate issues" (I13) or "I am actually a normal citizen" to the indirect assignment of science as a source of knowledge meaning "I am not a climate researcher" (I13) and "I honestly do not know the models in detail" (I8). It should be emphasized that in the context of climate change, both the professional role of the interviewee but also the position as a citizen are used to derive uncertainties and non-knowledge. However, knowledge about the presence and impacts of climate change regarding cod exists across interviewees, because if "climate change affects us all, [...] it naturally also affects the marine environment" (I3), only "in which direction it is going" (I13) cannot be clarified. The latter explicitly alludes to the uncertainties that can be attributed to climate projections. However, the influence of climate change and the uncertainty that arises is often linked to the migration behavior of cod as a cold water-loving species: "we just don't know whether it might also offer an opportunity for other species" (I3) or "[ . . ], another species might then gain disproportionately" (I13).

Besides the assigned role of fishers and scientific knowledge, in some examples, however, interviewees clearly state "I don't know." (I13), or "[ . . ], that would be pure speculation" (I11) without giving any indication of possible sources of knowledge. 
A detailed examination of the interviews content clearly shows that there is not only uncertainty in the perception and assessment of the stock and its drivers, but also nonknowledge among those involved in the cod-question. In some cases, responsibilities are differentiated and the role of fishers' knowledge ("A question that needs to be answered by practitioners." (I2)) or science ("This is what science has described." (I7)) as important is stressed.

\subsection{Science and Western Baltic Cod}

The scientific evidence about cod is framed by almost all interviewees as too insecure to provide a precise stock assessment bearing also an impact on the evaluation of management measures in general (for a detailed description of assigned subcategories, see Supplementary Material Table S3). This deficiency is basically attributed to the dynamic character of the system cod itself, the scientific methods applied and a gap in useful or applicable data to specify and make current analyses more precise. However, a somewhat general trust in science and its best intentions is expressed by many interviewees. This aspect can be seen in the following quote:

"Yes, I trust the scientists, they do their science in all conscience and try to estimate stocks correctly. But the models obviously contain certain deficiencies if not faults which entail considerable consequences. And I think that it is the responsibility of politicians to reflect these deficiencies [ ... ]." (I11)

To be emphasized, reference is made here to the so-called "model-question" showing the weaknesses of models and the problems resulting from them. The phrase "considerable consequences" highlights subsequent developments: it raises the issue of how these deficiencies become perpetuated in the realm of policy and become inbuilt and sometimes problematic ingredients in fishing policies and ensuing management measures. The general call to a responsible handling of uncertain model or scientific results becomes apparent here.

Besides such general aspects, the uncertainty of science also is divided into different dimensions and phenomena-natural mortality rates in the following example-which define certain areas in need of further research and a better scientific understanding. The image of "lies in the dark" in the following excerpt makes reference to a lack of visibility which in turn refers to light as clarity enabling vision and therefore knowledge:

"I think, the whole issue of natural mortality still lies in the dark and requires scientific research. The problem consists in the fact that natural mortality is almost constant in all models. We are not happy with this procedure." (I7)

The strategy to concentrate on a specific knowledge gap becomes clear and is connected to the need for further scientific research. Hence, deficiencies or knowledge gaps in science are not taken as such but are immediately linked to the need for further research ("requires scientific research") bridging and taming this lack. This demand is yet contrasted in the quote with an outline of the problematic practice of setting the parameter of mortality on a constant level in the respective models. This reflection is accompanied by an emotional framing depicting a scientifically tenable compromise ("We are not happy with this procedure"). However, knowledge gaps are related here to the usual practice of scientific tinkering in terms of doing research while also expressing dissatisfaction with this situation. The only solution to fill this gap and to provide firmer knowledge for an improved management though remains in more research.

Another scale of science becomes apparent in the following quote, which refers to the impact of certain developments in the stock in general and to the lack of predictive knowledge in special. The scale alluded to is social ("the scientists") and geographical as implicitly expressed by the metaphor "on the doorstep" which generates an imaginative framework of proximity and direct effects. Additionally, the phrase "none of the scientists" identifies a social group and attributes responsibility for the lack of knowledge about the development of the stock to them: 
"How this bears and impacts the stock, meaning what is going on, I would say none of the scientists would have been able to predict this development. I think this is really appalling, I mean that there is so little research on a stock living right on the doorstep." (I1)

This situation of science becomes even more difficult with regard to other social groups that frame problems revolving around fishing in various ways. Fishers, for example, conceptualize the sea, the species living in it as well as their inherent dynamics differently than scientists. The following quote exhibits the opinion that the appearance of rising fish stocks cannot solely be explained with the help of science:

"Well, that is a tricky and difficult topic for fishers, when you say, well guys, this is impossible... Because the basin, the maritime zone cannot be empty of fish. But if so from where does this proliferating stock come from?" (I2)

Such differences between scientific prediction and everyday experiences undermine scientific credibility. They point to diverse and sometimes contradicting forms of knowledge and evidences going beyond science itself. This is also mirrored in the spatial framing of the Baltic Sea as a "basin" which connotes water and implies most probably certain types of species living in it such as cod. This framing is complemented by the notion of "maritime zone" that renders the Baltic Sea a discrete spatial entity while also reference is made to the stocks that apparently proliferate in an unexpected way. These everyday experiences of harvesting fish from this supposedly empty basin contrast with scientific knowledge of a declining stock as informed by modeling. The reasons for this opposition lie between the life-world experience of social stakeholders such as fishers and the scientific epistemology of engaging with cod. The latter is now further analyzed with regard to its conceptual aspects and how these are assessed by those involved in or exposed to cod management.

\subsubsection{Perspectives on 'Cod-Epistemologies': Systems, Methods and Data}

Fisheries science is to a large extent based on a scientific rationale comprising measurements, field studies, statistical analyses and, in many cases, uses modelling to assess the development of fish stocks. This also applies to research on WB cod and represents a way of producing scientific knowledge for stock assessments and the development of management measures. We, however, take here another analytical route and provide an epistemological study of the research undertaken on cod in the Western Baltic Sea. Hence, the investigation addresses how the entity of cod is scientifically constructed, what analytical concepts and notions are applied to develop this construction and how this way of producing knowledge about cod is assessed by those involved in the cod question. For this to be achieved, we focus on three most salient and sometimes controversial aspects that emerged in the course of our interview analysis: (i) the system understanding of cod, (ii) the various methods used to explore the entity of cod and (iii) the closely connected aspect of data generation and availability.

To start with, various system understandings of cod exist. There are general statements, which suggest that a complete or $100 \%$ secure scientific knowledge about nature is simply not possible as the system is too complex to be studied and understood as a whole:

"Well I think that nature will not be $100 \%$ predictable. And I am not sure whether it is worthwhile to strengthen scientific expertise in terms of personnel and money for getting $1 \%$ better results which really might improve management. I would doubt this fact." (I9)

The statement "nature will not be $100 \%$ predictable" clearly sets an epistemological and normative scientific limit with regard to prediction and contrasts this with an economic argument: the small benefit of improving the scientific system understanding for one percent does not equal the investment to be made "in terms of personnel and money". Moreover, this investment is not expected to improve management. All in all, it is scientifically and economically seen as a non-profitable endeavor. 
The aspect of complexity with regard to the system cod and its relation to other subsystems within the overarching ecosystem such as seals also plays an important role. Consequently, the interaction among system components is often depicted, and the results of scientific research are highlighted while reference is, in many cases, also made to the remaining insecurity of this scientific knowledge. This uncertainty is based on the system's understanding in general or the conceptual framing of constitutive processes or elements within it. This can for example be the size of a population and the connected problem of measuring it:

"Marine mammals, well, they definitely have an impact. We know from foodstudies of grey seals that they can consume a considerable amount of cod. But the grey seal population in the Western Baltic is minuscule and its impact is consequently not measurable. Maybe, there are other effects." (I4)

Frequently, other aspects are mentioned causing developments in the system which are not understood. In many cases, solutions cannot be tackled or fully grasped because the amount or quality of data needed is too low or even non-existent. However, a cause-effect relationship is characteristic for such a system understanding requiring a certain degree of quantifiable data to scientifically explain and understand developments within the cod system.

Besides these aspects of measurability and the characteristics of a more or less scientific systems understanding, the results from this thinking and research are also assessed by interest groups or resource users who are not scientists. These qualified 'outsiders' are exposed to a systems thinking in the form of numbers of stocks or species that lead them to individually assess the current state of the cod stock:

"If one trusts the numbers which have been published in the recent years by the Thünen-Institute [federal research institute], we then have to consider the fact that the stock has been brought to its knees, that there will be considerable deficits in terms of cod." (I10)

Bearing in mind that one cannot count the total amount of cod in the Western Baltic Sea, the quote clearly relates to expected trends as generated by scientific system thinking and, though probably, statistical calculation and modelling. The reference made to "numbers which have been published in recent years by the Thünen-Institute" suggests this aspect and emphasizes via the temporal allusion "recent years" to a certain scientific credibility and representativeness in terms of an aggregated time series. The status quo of the stock is, moreover, metaphorically portrayed negatively as being "brought to its knees".

Besides the various and sometimes obfuscating questions revolving around a system thinking, issues related to methods and data generation are raised by our interviewees. Systems are in many cases conceptually conceived as interwoven or networked entities. Hence, reference is made to the multifaceted connections in a system and the consequential causalities. This causes methodological problems in terms of what variables for a stock assessment should be taken into consideration and with what data. These aspects become apparent in the following quote:

"It is all considerably interwoven, very complex. We start with a very small number of samples and then project what should be in the sea. We never have an overview over the total stock. We hence compartmentalize the stock, then we make a projection and then we gross up. There is a considerable uncertainty in this. But it is nevertheless sold as a safe result." (I2)

The quote clearly exhibits how scientific data are assembled, constructed and generated: a holistic systems understanding is outlined, evoking a system-image in which everything is connected to everything. Against this general background, a reductionist and deductive rational is promoted ("we start with a very small number of samples") in which a though small empirical basis is used for a grounded estimation. This methodological step is legitimated by the claim that one can never "have an overview over the 
total stock". Hereafter, the holistic vision and the reductionist necessities are assessed and used to legitimate the heuristic "compartmentalization of the stock" which forms the basis for the estimated development. This skillful and scientifically sound procedure is, moreover, characterized as "uncertain" and critically contrasted with the conceptual leap of taking it as the "real" state of cod-stocks out there in the sea. The final line in the quote metaphorically assesses the aspect of results becoming a tradable good in terms of "sold as a safe result" and criticizes this aspect. In sum, what we witness here is an insight into the methodological and epistemological ways of constructing scientific knowledge about cod.

Such scientific knowledge, including the generalization in terms of safe results, is often questioned among those involved in cod management. Population dynamics represent a difficult topic and require several methodological and epistemological steps about which various stakeholders have gathered some knowledge during the years of their involvement. Thus, scientific results are not taken for granted but are scrutinized on a theoretical, methodological and sometimes empirical level. One of the basic questions often revolves around the methodological aspect as to whether and how the stock and "its special biology could be exactly described":

"Concerning the Western Baltic cod, I think that the question should be given back to the scientists and one should ask whether the population dynamics and the parameters for sustainable use of the stock with its special biology could be exactly described, meaning that everything is clear." (I7)

The need for clarity ("everything is clear") in terms of visibility is in this quote metaphorically depicted and used to conceptualize knowledge. This image is applied against the background of the methodological understanding of "population dynamics" together with the "parameters for sustainable use". Both phrases refer to a relatively detailed knowledge of the interviewee about the scientific approach and the conceptual complexities of cod. These are played out against the though tentative aspect of whether safe knowledge about the special biology of the cod stock is possible at all. Hence, prevailing conceptual issues of an exact systems understanding for an envisioned "sustainable use of the stock" are raised and relegated back to science.

Comparable aspects are also addressed in the next quote. Here, the methodological aspects in terms of taking samples are depicted and contrasted with an assessment of fishers to whom the approach appears to be wrong at worst or inconsistent at best:

"We have here this one topic. Science leaves on the 5th of May. They exactly set sails on this very date and do their catch. And they wonder, oh dear, last year we fished more fish. This year nothing. Well, they need it for their statistical analysis, it has to be carried out that way. But no fisher understands this. He tells it the scientist every time. You should not fish here. There is no fish here in these and these weather conditions here. And the scientist says: No fisher, I have to do it due to reasons of statistical analysis." (I13)

What is shown here is a dispute about a different methodological approach to make stock size estimates mainly characterized by an interplay of different times, study locations and weather conditions, leading to different results. While the scientific approach is legitimated by an ongoing "statistical analysis", the way fishers gather their knowledge appears to be based on experiential knowledge gained over time. The incompatibility between these two approaches and their constituting parameters (different temporalities, dissimilar sites and, according to the fishers, weather conditions) lies at the heart of this mutual incomprehension and conceptual incompatibility. The results and the assessment of the stock understandably differ and socially materialize as disagreement.

A way to tame this methodological difference and pacify the ensuing incongruities consists in view of scientists in improving the data basis for producing scientific evidence. Data appear to be the most important entity or object which is expected to provide a remedy for disagreement. Various stakeholders, especially from scientific and governmental institutions, continuously refer to the need for more data: "For this, for all these 
things, [ ... ] we need more, more data" (I4). These data are conceived to close gaps in scientific knowledge and offer a more precise evidence. However, such a framing does not address possible conceptual inconsistencies in the systems understanding of cod and the consecutive modelling of stocks. Such aspects are ironically depicted in the following quote by an 'outsider' to science:

"So, you can think about it because yesterday mister [ ... ] said it in a meeting what he wishes for in the future. He said three times in a row: data, data, data." (I2)

The phrase "data, data, data" on the one hand emphasizes the real need for data, while the ongoing repetition on the other hand adds a critical if not ironic undertone to this aspect. This matches one prevailing picture of fisheries science among some stakeholders: science is perceived as considerably funded that simply does not deliver. By contrast, it continuously asks for more funds and more data to produce, somewhere in the future, an evidence-base for better predictions and management decisions. However, this picture is contrasted with another, namely poor data bases:

"That they do not ask the critical question, exactly mention the aspect, that the data basis is bad. I would have expected an outcry some years ago. [ ... ] They should outline that all they have in terms of evidence generating mechanisms is a crystal ball. This means, we believe but we do not know. And I do not accuse them, that they cannot do science. But I would have expected that they say: 'It is about time, we have to do something now.' But such an activity is still lacking." (I1)

The necessity for articulating scientific needs is expressed and combined with a personal astonishment about the silence of science in view of the bad basis of data. This behavior results in believing instead of knowing, as expressed by the metaphor of the "crystal ball" that connotes fortune telling. Repercussions are scientific imprecision, knowledge gaps which in turn bear an impact on the scientific evidence used to make and legitimate management decisions.

\subsubsection{Perspectives on Insecure Scientific Epistemologies}

Scientific knowledge in fisheries science appears, as we have seen, to be a tricky entity, and the aspects raised here about its generation make things even more complex, complicated and confusing. The various system concepts depicted, the different methodological approaches outlined, as well as various assumptions made and the notion of data as a consolidating remedy unraveled in the analysis exhibited the multifaceted and sometimes inconsistent epistemologies at work in fisheries science as seen through the interviewee's eyes. These bear a direct impact on the knowledge fabricated for management. They result in inconsistencies and imprecisions as referred to by various stakeholders and scientists, and as expressed, for example, by fishers who hold a different knowledge about fish as based on their epistemologies. More data, as expressed by scientists and institutional representatives, do appear to be one but not the only solution for the problems encountered. This is because they do not close the qualitative gap between the need for conceptual improvements of systems thinking and methods, and the implicit rationale of 'more data' generate better knowledge for stock assessments. So far, the analysis of our interviewee's perceptions indicates that knowledge about cod is imprecise due to the complexity of the Western Baltic Sea ecosystem and its subsystem cod. This conceptual and methodological gap cannot be addressed solely by increasing the amount of data to be used for analysis. We would rather suggest here that science about cod in the Western Baltic Sea (and likely in many other fisheries management cases) requires social re-organization and at the same time an extension of scientific evidence. 


\subsection{Management}

Our coding of the interview transcripts and the derived subcategories give us a deep insight into fisheries management at the different levels of action (EU, national and local levels) including a detailed description of various management measures as well as the participation of stakeholders within management. In addition, the state of the management, its problems and possible improvements are outlined below (see Supplementary Material Table S4 for a detailed description).

\subsubsection{The Current State of the Baltic Sea Fisheries Management}

Our detailed analysis revealed that the interviewees express various views on current fisheries management problems and possible improvements. Concerning current management procedures to quota distribution, the following quote is paradigmatic:

"And one says, you still, you, the member state, still owe me something. Because I gave privileges to you back then, during the banana contingent and I now want to get a bigger share here. There is a mercatorial element included. Trade. Dithmarscher horse market, yes. (I2)"

The metaphor of the "horse market" refers to the bigger, money-valued trade between several market levels. Trade is not restricted to one sector such as fisheries, and decisions often interact with those in other sectors such as agriculture. Here, trade takes place continuously at all levels such as a "horse market" taking place frequently. The fisheries sector rather obtains small monetary shares with this market, hence the trade. As member states "owe" something to each other, it becomes clear that the catch quota distribution is often conditional on negotiations between the different sectors. This trade-off between the fisheries and other sectors is also raised by a further interviewee where the process is called "dealing" (I1) between fisheries ministers. This implies that the ministers exchange money economically in a large dimension-meaning catch quotas in fisheries management-between member states. These choices are made due to "actions causing the least resistance" (I2) between stakeholders involved. The representation of interests within the trade-off process, which "is not like in the past anymore" (I7), became less profitable for fishers. Given the diverse underlying trades between sectors and rather small shares for the fishery sector in fisheries management, interviewees express divers opinion on the manner of how well the WB cod stock is currently managed.

As some interviewees agree that cod stocks are currently well managed and that management is taking the right direction, other interviewees express diverse opinions. Positive opinions are articulated with statements such as the following:

"Exactly. I guess, I won't implement more than what we have so far. I think we will reach our aim with the measures which are currently implemented in alignment with the fisheries policy." (I9)

Current management measures are conceived as sufficient to reach the goals set by the EU to promote the sustainable exploitation of WB cod. It is also mentioned that the current actions taken are the "exact ones needed to reach the aim as fast as possible" (I7). "Exact the ones" shows that from the broad range of possible measures the correct ones were chosen and that no further thinking about alternatives is required. Another interviewee supports the execution of current procedures with the fact that "it is decided now and needs to be implemented. Because deviating from this would make it worse" (I1). The fact of "making it worse" shows that the policy implemented is currently the best at hand, and no alternatives are available. It also refers to the fact that fish stocks are in a bad state and that improvement by management measures is needed.

Further interviewees add a time aspect to the positive connotation of the current measures: "in the short term, everything needed is done" (I4) or "much more cannot be done in the short term" (I6). The temporal aspect as expressed via "short term" determines the limits of successful implementation. The measures appear to be sufficient for now, but taking long-term aspects into account, they seem to be insufficient for a sustainable 
management of the cod stock in the Baltic. In brief, short-term measures are the fastest and easiest to implement, whereas now is the time to create long-term measures.

Opponents, in contrast, declare that "there is no sustainable management for 100 percent" (I13) and the fisheries management is "catastrophic" (I13) and has failed:

"So, in retrospect, one has to say the management has failed because the stock is simply gone. That is the clear evidence." (I8)

"Simply gone" and "clear evidence" explicitly frame the negative situation of the cod stock. It appears that cod has disappeared under the supervision of the policy makers, who are now confronted with the fact that their management did not work. The "catastrophic" aspect shows the felt and urgent need for improvement and puts management as well as decision makers under immense pressure.

In the context of poor management, the time aspect is perceived as the duration of bad management as expressed in "and this has been managed badly for eight or nine years by politicians being aware of that" (I4) or "No, of course not. Otherwise he wouldn't have collapsed. He wasn't managed sustainably for 20 years. And this has led to the current precarious situation"(I4). "Managed badly" and "wasn't managed sustainably" depict the severe situation and how it has failed over multiple time periods. The phrase "precarious situation" clearly frames the current state of the management and puts it in the grim position of no prospect of success.

Interviewees also mentioned that the management did not reach the aims of a multiannual measure implementation:

"The stock will be managed, governed, and the common aim is to manage it at the MSY-level. We are not there yet." (I7)

"Not there yet" is a metaphor for a path, which is currently 'walked' to achieve a sustainable cod stock. The management is on the right track, but the aim has not been reached yet. Further support of the statement is given by one interviewee, who said "there would be the case where the cohort is managed in a good way and might increase in numbers, but this is nearly impossible until 2020" (I8). Moreover, "not there yet" emphasizes a chance to achieve a sustainable management of the stock, whereas "nearly impossible" rather pictures a strongly diminished chance.

As we have seen, the current way of fisheries management is framed differently between the interviewees. It lies within a complex policy system where different sectors are involved and so-called trade is taking place. The fisheries sector is forced constantly to consider other sectors' privileges, which makes implementing management measures on its own rather impossible. Whereas some interviewees agree that the current state of the management is sufficient to support the recovery of cod, others argue for improvements.

\subsubsection{Problems}

The analysis of the interviews, furthermore, highlights that concern exists regarding the current management of cod. As raised by one interviewee, the scientifically established maximum sustainable yield (MSY, a fishing reference level to sustain sustainable stock development) approach is not fully implemented by the policy makers: "As I said, I think it would have been good for all participants if one would have focused on the MSY goal 2020 on time." (I13)

The temporal aspect of "on time" underlines that policy makers failed to focus on fisheries goals and started their adjustments in terms of management too late. These adjustments have consequently to be carried out in a stricter and intensive way bearing bigger influences on the fisheries sector and the connected economy. This failure of management for several years is also going hand in hand with concrete scientific quota proposals:

"Science recommends to reduce for further 20 percent, and they [policy makers] only reduce for 10 percent, and that is how the stock becomes steadily smaller and smaller. There is no way out of this spiral." (I4) 
The policy makers kept the cod quota higher than the scientific advice for several years. The image of the "spiral" highlights the drastic situation and presumes, in this context, a way down, where there appears no chance for the stock to recover. The follow-up problem consists of the lack of transparency for the reason of higher cod quota: "It is fundamentally non-transparent why catch quotas are set above the scientific recommendations" (I11). This lack of transparency is an important issue concerning catch quota distribution, which appears to be a "not really transparent process" (I5). The underlying reasons explaining the catch quota distribution process are missing, which creates conflicts due to lack of knowledge and can cause distrust among stakeholders.

Further complications are mentioned in relation to multiannual plans. These plans imply the common fisheries policy (CFP) including the aim for fish stock being exploited at sustainable levels or the control and implementation of fishing effort restrictions over multiple years [62]:

"Of course, something happened in the first year, which was not taken into account during the composition; the complete failure of the year 2015. The plan did not have enough flexibility for this unexpected situation. Simply interfere with the fisheries activities and take away 80 percent of the quota: that is not sustainable." (I7)

The aspect of lacking "flexibility" of the plans is a complicated issue. Yearly failures of recruitment can occur due to environmental changes, which makes it difficult to stick to commonly developed practice when these unexpected situations happen. "Flexibility" would broaden the capacity of adaption for the economy and fishers. Furthermore, "simply interfere" represents the diminished possibility for fishers to intervene in these severe situations, since management plan was set. They have to follow the policies and measures implemented with no space for negotiation or flexibility.

The main topics of current problems include the failure of policy makers to react on time to the stock decrease, the non-transparent processes of catch quota determination given scientific advice, as well as complications due to lacking flexibility in multi-annual plans. These problems lead to distrust of stakeholders in the management and have great implications for fishers, whose livelihoods largely depend on the catch quota and thus the amount of fish they are allowed to catch. Based on these issues, the interviewees propose suggestions for an improvement of management to enhance flexibility and risk minimization due to unexpected stock failures.

\subsubsection{Improvements}

Given the accounts about the current way of cod management and its problems, the interviewees proposed improvements with respect to flexibility, long-term planning and scientific advice:

"And as the next step: that the policy can react fast to it. It is important to have a really good stock, so with the years you can say flexibly: okay, the anglers don't need the bag limit anymore and the fishers can go up a bit. And in the next year it can be decreased rapidly. So, it would be, I think, very important to include a certain flexibility." (I10)

In alignment with one of the problems, lack of flexibility, the interviewees raised the issue for improvement. It is noteworthy that the interviewee mentions the relevance for a "fast" reaction of policy makers and emphasizes the "flexibility" of providing quickly adjustable catch quotas to fishers. "Fast" refers to the fact that current reactions are perceived as rather slow, whereas "flexibility" in contrast demands rapid changes. Flexibility would provide decision makers with the chance to conduct short-term measures with rather smaller impacts on fishers and economy instead of implementing harsh regulations to react to a too severe situation. In alignment with the flexibility, interviewees suggest to implement a long-term management: 
"My immediate measure would be to directly start thinking about setting up a long-term management and to implement this for 100 percent, to create safe circumstances for all participants." (I13)

"[D]irectly" and "100 percent" illustrate the need for a change and safety in the management. The actions need to take place now to ensure "safety" for the participants, so that they can rely on agreed management measures in cases of unexpected situations. The statement is also supported by one interviewee who proposes to "integrate enough buffer, think a bit more in mid- and long-terms" (I6). The buffer would make it easier for decision makers to decide during unforeseen developments and provides security for the resource users. The long-term planning is also associated with a learning process from the past:

"I can only express the wish that one thinks more in longer terms for the future, to plan proactively and to learn from mistakes made in the past." (I1)

It becomes clear from "proactively" that this aspect is not part of current management. "Mistakes" also include that responsibility lies solely on each stakeholder group, but the idea is to spread responsibility across the various groups (I1).

As the aspect of TAC settings is implemented on a yearly approach, it seems rather impossible to plan more years ahead. To ensure a better safety and probably also transparency within the process itself, the need for long-term management is stated quite often by the interviewees. Even though the multiannual plan for cod, herring and sprat in the Baltic Sea was adopted in 2016 under the new CFP [62], several interviewees still call for a long-term solution to be implemented for WB cod.

Another suggestion to improve the lack of safety in terms of economic projectability was mentioned concerning scientific advice:

"The EU needs to be oriented towards and implement the scientific advice. Then, they don't have to live with the insecurity anymore and the stock could recover, and would have the room to vary, which would also minimize the risk." (I12)

The direction of the EU in this context does not consider the scientific basis that is needed to manage the stock in to a sustainable condition. The criticism about management giving higher catch quotas than scientific advice suggested is seen as a chance for improving the situation. The positive consequences of such an improvement mentioned are the stock recovery or the increasing security given a "risk" minimization. "[T] he risk" represents the great uncertainty for fishers due to strong reductions of catch quotas. The insecurity is also mentioned in the context of science, where it represents the uncertainty of catch quota ranges:

"But in a system with this high variety like the Western Baltic Sea or the Baltic Sea in general, this will reoccur to us constantly. And what I always propose to politicians in this case is to not concentrate that much on what they can do with even more money, but they should accept the uncertainty which we specify. Make your management that robust that it is not built upon less than 10 percent uncertainty. I don't want to say mistake. Because these are not mistakes, but it is uncertainty." (I4)

What is depicted here are the ingredients and aspects of "robust" management. Robust management lies within "decision making under deep uncertainty" which entails complex systems that are difficult to estimate and where experts have diverse opinions on the system's functions and its relationships [63-65]. The models, capturing this deep uncertainty, analyze different possible choices against different compelling futures [66], from which robust management trade-offs are developed as tools for promising the management of socioecological systems [67]. For the cod management, this requires a lot of cautiousness from decision makers who have to deal with several aspects: environmental variability, insecurity of the fishers, the economy and the uncertainty provided by scientific advice. "Robust", however, means that management can withstand all uncertainties and still satisfies all stakeholders affected. The proposal for this tricky situation consists of the 
suggestion for managers to focus less on money-related issues but rather consult science to incorporate its advice into management.

From the detailed analysis of the interviews, we gained various perspectives and descriptions on the current management situation, its inherent problems and suggestions for improvements. The opinion on whether management is sufficient differs among interviewees, as well as their consecutive argumentation for or against certain measures. Nonetheless, fisheries management has not prevented the stock from reaching a depleted state and is not achieving a recovery of the stock. Problems raised by interviewees include management timing (i.e., implementation of measures seems to occur far too late), flexibility in catch quota allocation and management adjustments (i.e., ability to respond to unforeseen events such as stock failures). More flexibility in the catch quota allocation is primarily suggested to mitigate the impact on fishers and their livelihoods. However, interviewees did not describe what this flexibility might entail. In addition, they say that better implementation of scientific advice would improve the situation of the WB cod fisheries.

\section{Discussion}

The interviews we conducted reveal a broad spectrum of existing problems but also hold possible solutions to support a sustainable harvesting of fish stocks. Above all, they provide potential entry points to generally make the fisheries sector more stable and sustainable for the future. The interacting and mutually dependent issues of knowledge, science and management were conceived as relevant by our interviewees and provided a comprehensive insight into the manifold problems revolving around WB cod.

We have shown that there are various 'knowledges' in the consideration of cod as a species ranging from historical knowledge, biological knowledge and tacit knowledge to economic knowledge. Such diversity in the description of cod and its related ecological, economic and social dimensions reflects a multilayered picture among various stakeholders and demonstrates different lenses through which this species can be seen (Figure 3). Furthermore, we have shown how cod is conceptualized in different scientific ways, leading to a jumble of framings which lack the challenging task of an integrated understanding of the cod system itself (Figure 3). This not only leads to mistrust among various stakeholders but also to conflicts that arise from the methods used to collect data and the resulting conclusions drawn from them. Thus, there are not only gaps in scientific knowledge, which nestle in the limitations or diversity of methods and models, but there are various framings based on various ways of 'knowing' cod. These aspects become apparent in the framing of cod management where different perspectives were identified mirroring current problems on the local, national and EU level while also calling for improvements (Figure 3). The analysis revealed multiple points of criticism, e.g., that management lacks flexibility (i.e., rapid response to environmental, economic or social changes) or transparency in the allocation and distribution of fishing quotas. There are, moreover, calls to better implement a long-term management plan that would not only safeguard the stock but also fisheries. One way forward could be to use approaches in which 'knowledges', scientific evidence and management options can be negotiated in an open-ended and symmetrical way (Figure 3). This would generally mean to make the process a more social endeavor in which the ecological and the social hold equal places. 

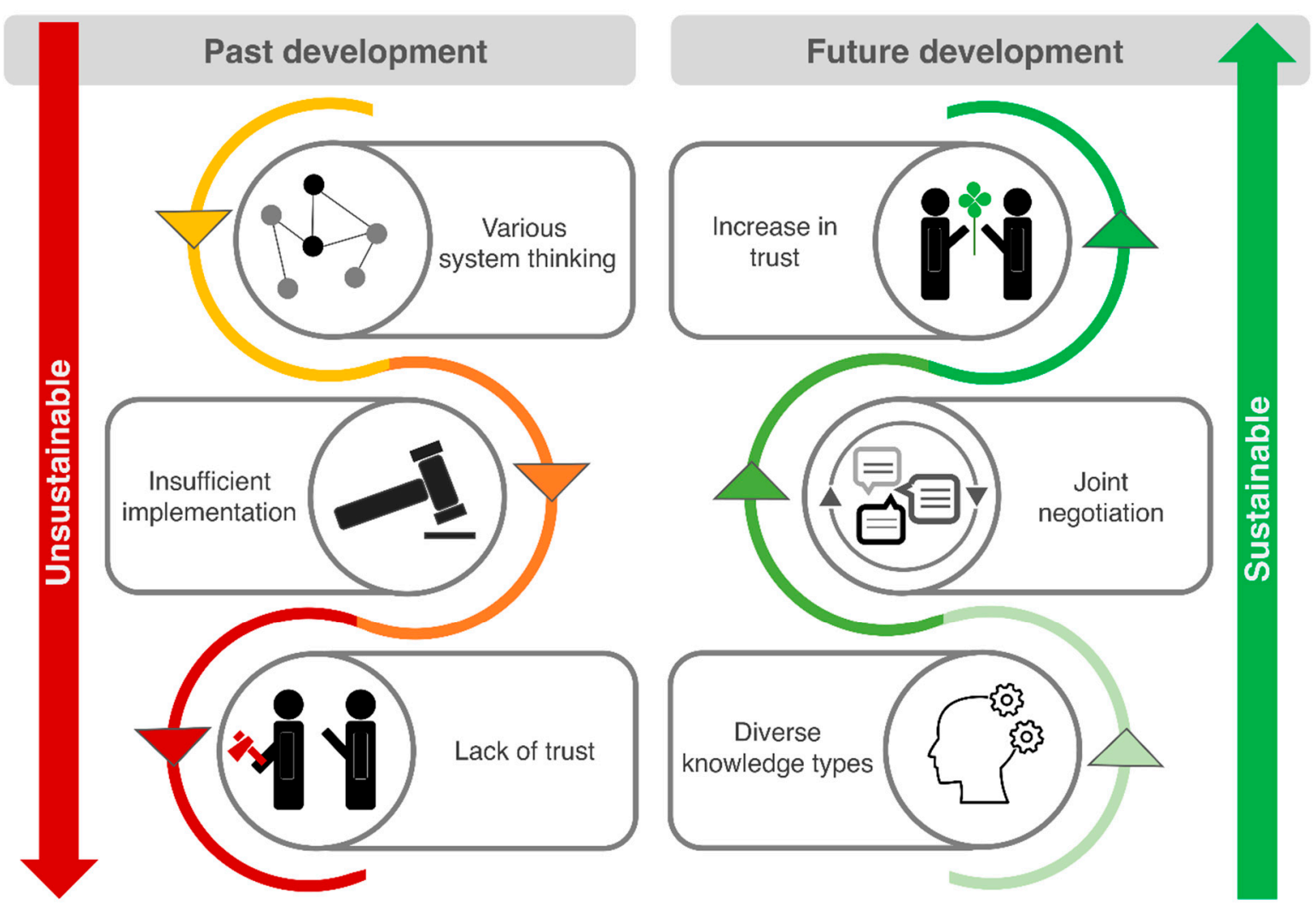

Figure 3. Circle of trust implying un- and sustainability. The analysis has shown that the management of European fish stocks is characterized, in part, by a lack of flexibility and transparency in the allocation of fishing quotas, leading to conflict and mistrust among resource users and interest groups. First and foremost, there are diverse system understandings and the resulting different conceptualizations of system components, system functioning and system dynamics (various system thinking). In the past and still today, there is a lack of recognition of this knowledge diversity and suggestions on how to implement this in management (insufficient implementation). This aspect reflects a past development that is not sustainable and develops into a picture that is nowadays characterized by mistrust and a lack of acceptance of management decisions (lack of trust). To ensure a sustainable exploitation of natural resources, and in our case fish stocks in EU waters, there is a need to redesign the participation processes within the management system. There is a huge spectrum of different types of knowledge or 'knowledges' generated by various user and interest groups. In order to reverse the resulting downward loop of management development, it is necessary to recognize and integrate these knowledge types into the management process (diverse knowledge types). This step should be followed by a participatory process involving different users as well as interest groups to gather their perspectives on the system itself and management (joint negotiation). The main objective consists of building or rebuilding trust between the different stakeholders in the system with the intention to develop integrated management decisions and consequently to ensure a sustainable use of natural resources (increase in trust).

\section{The Theoretical and Methodological Entrance to the Multifaceted Species Cod}

The basic assumption that human activity affects nature and therefore fish [2] opened up the possibility to theoretically study cod in its entirety and to explore its diversity from different angles. However, in order to turn cod into a manageable species, a legitimate scientific classification is developed which provides the basis for fisheries management not only of WB cod. However, there is a growing interest in understanding cod not only from the scientific perspective but also in attributing a growing role to stakeholders' framings of the system. This assumption that cod is not a homogeneous object and cannot exclusively be classified by science has provided space to think about cod in a more comprehensive way. The idea of the so-called "cod multiple" [12,31,42] provided the opportunity to comprehensively understand this species, to enlarge and discuss problems revolving around this stock. This theoretical approach allowed us to reframe cod from different biological, economic and social perspectives. 
The aspect to understand management as co-construction and to negotiate and involve different 'knowledges' [21] encouraged us to explicitly focus in our approach on the investigation of the different 'knowledges', the framing of science and management. This now enabled us to provide food for thought that could help to make management more participatory and thus represent a contribution to the sustainable use of WB cod in particular and natural resources in general. However, it should be realized that integrating more and different 'knowledges' does not automatically improve the interaction between different stakeholders and increase the acceptance of management decisions as well as their implementation in practice. However, the awareness of the different 'knowledges' and their backgrounds can lead to the support of better mutual understanding which can be understood as a first step to manage the system and its components in a more sustainable way.

In this context, it is relevant to emphasize that knowledge about and framings of a system can be generated and determined through multiple ways (e.g., experiences and analysis). In general, different understandings and framings of a system can be explained by the fact that people interact in very different ways with the system itself or system components such as fish species that are, for example, directly (practicing fishing) or indirectly (modeling fish distribution) related to the biological system. These different ways of generating knowledge lead stakeholders to develop different perspectives on and understandings of the biological 'workings' of natural resources-or in our case, WB cod [68] — and the resulting management options [17].

It has, moreover, been shown that there are different ways and practices of scientists and fishers to frame the state of fish stocks. While a fisher trusts his on-board equipment to iteratively follow fish to catch it (i.e., fine spatial scale and local) and observes stock from their on-boat or practice perspective, researchers use scientifically standardized routes to estimate stock size through scientifically sound and robust epistemologies (i.e., large spatial scale and universal) [69-72]. The assessment of and knowledge about stock size is thus not only determined by different technologies but rather by the background of different epistemologies, rationales, practices and approaches. These aspects cause variations in the framing of problems, meaning not only which problem is perceived, but how it is constructed, socially embedded and what finally has to be done about it. Diverse epistemologies are important as they allow a fish stock to be explored at different scales, providing a comprehensive picture of it as well as its surrounding system [71]. The intent, therefore, should be to acknowledge different epistemologies and indicate that natural resource management should incorporate a broader variation of 'knowledges' to reflect current ecological, social and economic changes $[25,73-75]$ and what to do in relation to them.

In order to ultimately reveal, explore and recognize these 'knowledges', it is important to consider how stakeholders can be effectively involved in the context of natural resource management and at what levels this can take place. This process can be organized and designed in many different ways, depending on the organizational level, but also on the resources available (e.g., time), as well as the specific intention of the stakeholder participation and the intended forms of possible interaction see [74,76].

In the context of European fisheries management, there are numerous considerations of co-management approaches, but the attempt to implement them seems to be blocked in parts by top-down driven management [77]. However, there are two EU initiatives that have been established to institutionalize and thus strengthen stakeholder participation at regional (e.g., AC, Advisory Council) and local levels (e.g., FLAG, Fisheries Local Actions Groups) [50,78-80].

ACs were implemented with the aim to increase involvement of various groups in fisheries management (e.g., commercial fisheries and NGOs) to support discussion across stakeholders and develop various ways of cooperation $[49,50,78,81]$. The main task of ACs consists of formulating recommendations for the European Commission on aspects of the European fisheries management [50]. These include advice on the compliance 
with socioeconomic aspects of the management (e.g., implementation of new fishing gear) or simplification of rules for commercial fisheries [78]. It should be noted that these recommendations by the ACs only have a consultative function and are not subject to any implementation obligation. This kind of stakeholder involvement in fisheries management could be seen as a positive first step. However, there is also criticism with regard to the ACs (i) due to the unequal distribution of representatives given the majority of fisheries representatives (60:40, i.e., fishing industry:other groups), (ii) to limited attendance due to resources such as time or money and (iii) to the difficulties of finding consensus due to diverse regional and local issues $[48,50,81,82]$.

FLAGs, unlike ACs, are based at the local level and involve not only fisheries and eNGOs but also the public and private organizations $[78,79]$. The goal here is to design joint strategies that benefit the development of local fish communities (e.g., an app to support direct marketing for local fish) [80]. While ACs tend to involve large-scale fisheries, FLAGs are more likely to involve small-scale fisheries [78]. As far as the influence of FLAGs on decision-making processes is concerned, they can rather be understood as offering a possibility for co-management, which is strongly dependent on local realities and willingness. Linke and Bruckmeier (2015) show examples in which FLAGs clearly distances themselves from political activities, while others want to actively influence politics and its actions. For some FLAGs, direct participation in local decision-making is even described, through which, e.g., spatial planning processes could be influenced by fisheries [78]. In this context, it is important to note that a FLAG can be related to different topics such as (i) society and culture, (ii) added value to fisheries, (iii) environment, (iv) diversification and (v) governance. The latter objective aims to strengthen the role of fishing communities in the local development and governance of local fisheries resources, thus giving fishers a voice in local decision making and resource management [80]. In this regard, MiretPistor et al. (2020) noted that only a few of the reviewed projects focused on this objective. However, other overarching goals of FLAGs would also contribute to governance [79], although a critical review reveals that the focus is only on knowledge sharing and not on actual power sharing.

It should be noted that there are already initiatives established by the EU that enable the participation of various stakeholders, which, unfortunately, only provide for limited power sharing. In general, however, it must be stated that communication and interaction between resource users and interest groups in many ways is a first step toward a jointly managed resource. However, this needs to be socially institutionalized in order to build trust at the lowest level and thus create acceptance of, for example, management decisions in the second step. This engagement with resource users and stakeholders is time intensive and requires a lot of care to lay the foundation for trust, not only between stakeholder and scientist but also with the stakeholder group itself. Time-wise, this step is often underestimated, due to projects being set up for too short a time, which does not allow firm social structures to be built up. Approaches to highlighting in this context are Community of Practice [83] or Living Lab [84]. Both approaches focus on a similar start (e.g., topic and, if applicable, conflict shared by the stakeholders) and the establishment of defined ways of working to create an initially informal social institution [83,84]. A positive aspect to be emphasized is a given long-term planning capability (e.g., by long-term funding), which helps to establish a social system in a multifaceted exchange with the stakeholders on the ground. What is missing here, as already described in parts for ACs and FLAGs, is the "real" power to concretely influence and change management design and measures. Of course, it is possible to involve mayors or ministers, but again, there is no general guarantee that developed proposals for change in natural resource management will actually be implemented.

Lastly, it is important to note that, especially in the context of EU management, there are multiple ways to involve stakeholders in fisheries management, but in most cases, this form of involvement is limited to knowledge sharing rather than stakeholder empowerment. 


\section{Conclusions}

To conclude, we have highlighted the different stakeholder 'knowledges' and perspectives that frame Western Baltic cod and its surrounding systems. Likewise, we exposed the time dimensions that permeate WB cod at the scientific, political, administrative and social levels, leading not least to divergent temporal frames that have created conflicts or, as in our case, harden them.

As to the present state, it seems that a kind of endless and rather unsuccessful loop has developed over the recent decade that is calling for integrated action more than ever. Top-down EU fisheries management has contributed to overfishing (and stock depletion), in which fishing pressures (e.g., catch quota) have been too high and predictions have been false due to model uncertainty and environmental change [39]. This resulted in a lack in trust among fishers, politicians and scientists.

Therefore, actions that increase stakeholder involvement at multiple levels of governance, i.e., local, national, and supranational, have the potential to promote confidence in and acceptance of management measures, one of the keystones of achieving a sustainable exploitation of marine resources. This shift would mainly address the aspect that management needs to be designed in a more social way, meaning to be more participatory in terms of negotiation while acknowledging the various 'knowledges' and perspectives on the 'cod-multiple'. Our study hence emphasizes the need to better implement ecosystembased management in EU fisheries of which a social-ecological system approach is a key component [85-87]. Even if this path requires more time and financial resources, it can address the sustainability goals set within the EU [88].

Supplementary Materials: The following are available online at https: / www.mdpi.com/article / 10.3390/su132112229/s1. Accompanying our manuscript, we present additional information on the stock assessment of Western Baltic cod and measures taken to manage this stock sustainably. The document also includes the interview guide consisting of questions on ecology, management, economy, communication as well as conclusion and ideas for solutions. Also included are the detailed descriptions of the three categories knowledge, management and science and their empirical subcategories, as collectively identified during interview analysis.

Author Contributions: Conceptualization, H.S., A.M.B. and M.D.; methodology, M.D., A.M.B. and H.S.; formal analysis, H.S., A.M.B. and M.D.; investigation, H.S., A.M.B. and M.D.; resources, H.S. and C.M.; data curation, H.S.; writing-original draft preparation, H.S., A.M.B. and M.D.; writingreview and editing, C.M.; visualization, H.S., A.M.B. and M.D.; project administration, H.S. and C.M.; funding acquisition, C.M. and H.S. All authors have read and agreed to the published version of the manuscript.

Funding: H.S. was funded by the Ph.D. Scholarship Programme of the German Federal Environmental Foundation (Deutsche Bundesstiftung Umwelt, Osnabrueck; no. 2017/480) and by the Federal Ministry of Education and Research, balt_ADAPT (no. 03F0863D). M.D. was funded by the cluster of excellence Climate, Climate Change and Society (German Science Foundation) situated at the University of Hamburg. A.B. was funded by Federal Ministry of Education and Research, SeaUseTip (no. 1LC1825A-C).

Institutional Review Board Statement: All subjects gave their informed consent via email for inclusion before they participated in the study. This also applies for the citation of quotes from interviews which have been anonymized. The study was hence conducted in accordance with the Declaration of Helsinki.

Informed Consent Statement: Not applicable.

Data Availability Statement: The data presented in this study are available on request from the corresponding author. The data are not publicly available due to restrictions, i.e., privacy and ethics.

Acknowledgments: The interview guide development and the interviews were conducted as part of the "Advanced Fisheries Science" course of the MSc program in "Marine Ecosystem and Fisheries Sciences" (MARSYS) at Hamburg University. We thank all students for their participation and work in this project. We also thank the reviewers for their constructive comments. But the most, we 
would like to sincerely thank all stakeholders who shared their knowledge, views, uncertainties and concerns with us. It was only through your cooperation that we were able to explore the Western Baltic Sea and in particular Western Baltic cod from so many exciting perspectives.

Conflicts of Interest: The authors declare no conflict of interest.

\section{References}

1. Berkes, F. Sacred Ecology, 2nd ed.; Routledge: New York, NY, USA, 2008; p. 394.

2. Pálsson, G. Nature and society in the age of postmodernity. In Reimagining Political Ecology; Biersack, A., Greenberg, J.B., Eds.; Durham University Press: Durham, NC, USA, 2006; pp. 70-93.

3. Johnson, P.J.; Hersoug, B. Local empowerment through the creation of coastal space. Ecol. Soc. 2014, 19, 1-7. [CrossRef]

4. Latour, B. An Inquiry into Modes of Existence: An Anthropology of the Moderns; Harvard University Press: Cambridge, MA, USA, 2018; p. 489.

5. Latour, B. Reassembling the Social: An Introduction to Actor-Network-Theory; Oxford University Press: Oxford, UK, 2007 ; p. 312.

6. Jefferson, R.; McKinley, E.; Capstick, S.; Fletcher, S.; Griffine, H.; Milanese, M. Understanding audiences: Making public perceptions research matter to marine conservation. Ocean Coast. Manag. 2015, 115, 61-70. [CrossRef]

7. Dobson, A. Citizenship and Environment; Oxford University Press: Oxford, UK, 2004; p. 240.

8. Dobson, A.; Bell, D. (Eds.) Environmental Citizenship; MIT Press: Cambridge, MA, USA, 2005; p. 296.

9. Fletcher, S.; Jefferson, R.L.; McKinley, E. Saving the shallows: Focusing marine conservation where people might care. Aquat. Conserv. 2012, 22, 7-10. [CrossRef]

10. Guest, H.; Lotze, H.L.; Wallace, D. Youth and the sea: Ocean literacy in Nova Scotia, Canada. Mar. Policy 2015, 58, 98-107. [CrossRef]

11. Berkes, F.; Nayak, P.K. Role of communities in fisheries management: One would first need to imagine it. Marit. Stud. 2018, 17, 4 . [CrossRef]

12. Probyn, E. Eating the Ocean; Duke University Press: Durham, NC, USA, 2016; p. 202.

13. Voyer, M.; Gollan, N.; Barclay, K.; Gladstone, W. 'It's part of me': Understanding the values, images and principles of costal users and their influence on the social acceptability of MPAs. Mar. Policy 2015, 52, 93-102. [CrossRef]

14. Hannigan, J. Toward a sociology of oceans. Can. Rev. Sociol. 2017, 54, 8-27. [CrossRef] [PubMed]

15. Yates, K.L.; Clarke, B.; Thurstan, R.H. Purpose vs performance: What does marine protected area success look like? Environ. Sci. Policy 2019, 92, 76-86. [CrossRef]

16. Pita, C.; Pierce, G.J.; Theodossiou, I.; Macpherson, K. An overview of commercial fishers' attitudes towards marine protected areas. Hydrobiologia 2011, 670, 273-281. [CrossRef]

17. Schwermer, H.; Aminpour, P.; Reza, C.; Funk, S.; Möllmann, M.; Gray, S. Modeling and understanding social-ecological knowledge diversity. Conserv. Sci. Pract. 2021, 3, e396. [CrossRef]

18. Yates, K.L. View from the wheelhouse: Perceptions on marine management from the fishing community and suggestions for improvement. Mar. Policy 2014, 48, 39-50. [CrossRef]

19. McKinley, E.; Fletcher, S. Improving marine environmental health through marine citizenship: A call for debate. Mar. Policy 2012, 36, 839-843. [CrossRef]

20. Moon, K.; Cvitanovic, C.; Blackman, D.; Scales, I.; Browne, N. Five questions to understand epistemology and its influence on integrative marine research. Front. Mar. Sci. 2021, 8, 173. [CrossRef]

21. Alexander, K.A.; Hobday, A.J.; Cvitanovic, C.; Ogier, E.; Nash, K.L.; Cottrell, R.S.; Fleming, A.; Fudge, M.; Fulton, E.A.; Frusher, S.; et al. Progress in integrating natural and social science in marine ecosystem-based management research. Mar. Freshw. Res. 2019, 70,71-83. [CrossRef]

22. Danovitch, J.H.; Keil, F. Should you ask a fisherman or a biologist? Developmental shifts in ways of clustering knowledge. Child Dev. 2004, 75, 918-931. [CrossRef] [PubMed]

23. Moreno-Báez, M.; Orr, B.J.; Cudney-Bueno, R.; Shaw, W. Using fishers' local knowledge to aid management at regional scales: Spatial distribution of small-scale fisheries in the Northern Gulf of California, Mexico. Bull. Mar. Sci. 2010, 86, $339-353$.

24. Teel, T.L.; Anderson, C.B.; Burgman, M.A.; Cinner, J.; Clark, D.; Estévez, R.A. Publishing social science research in conservation biology to move beyond biology. Conserv. Biol. 2018, 32, 6-8. [CrossRef]

25. Stephenson, R.L.; Paul, S.; Pastoors, M.A.; Kraan, M.; Holm, P.; Wiber, M.; Benson, A. Integrating fishers' knowledge research in science and management. ICES J. Mar. Sci. 2016, 73, 1459-1465. [CrossRef]

26. Moon, K.; Browne, N.K. Developing shared qualitative models for complex systems. Conserv. Biol. 2021, 35, 1039-1050. [CrossRef] [PubMed]

27. Murdoch, J.; Clark, J. Sustainable knowledge. Geoforum 1994, 25, 115-132. [CrossRef]

28. Clark, J.; Murdoch, J. Local knowledge and the precarious extension of scientific networks: A reflection on three case studies. Sociol. Rural. 1997, 37, 38-60. [CrossRef]

29. Amariglio, J. Poststructuralism. In The Handbook of Economic Methodology; Davis, J.B., Hands, D.W., Maki, U., Eds.; Edward Elgar: London, UK, 1998; pp. 382-388.

30. Latour, B. We Have Never Been Modern; Harvard University Press: Cambridge, MA, USA, 1993; p. 168.

31. Law, J. After Method. Mess in Social Science Research; Routledge: London, UK, 2004; p. 200. 
32. Abram, S.; Lien, M.E. Performing nature at World's ends. Ethnos 2011, 76, 3-18. [CrossRef]

33. Lien, M.E.; Law, J. 'Emergent aliens': On salmon, nature, and their enactment. Ethnos 2011, 76, 65-87. [CrossRef]

34. Todd, Z. Fish pluralities: Human-animal relations and sites of engagement in Paulatuuq, Arctic Canada. Inuit Stud. 2014, 38, 217-238. [CrossRef]

35. Holm, P. Which way is up on Callon? In Do Economists Make Markets? On the Performativity of Economics; MacKenzie, L.S.D., Muniesa, F., Eds.; Princeton University Press: Princeton, NJ, USA, 2007; pp. 225-243.

36. Eden, S. Counting fish: Performative data, anglers' knowledge-practices and environmental measurement. Geoforum 2012, 43, 1014-1023. [CrossRef]

37. Bavington, D. Managing to endanger: Creating manageable cod fisheries in Newfoundland and Labrador, Canada. Marit. Stud. 2009, 7, 99-121.

38. Bear, C.; Eden, S. Thinking like a fish? Engaging with nonhuman difference through recreational angling. Environ. Plan D 2011, 29, 336-352. [CrossRef]

39. Möllmann, C.; Cormon, X.; Funk, F.; Otto, S.; Schmidt, J.; Schwermer, H.; Sguotti, C.; Voss, R.; Quaas, M. Tipping point realized in cod fishery. Sci. Rep. 2021, 11, 14259. [CrossRef] [PubMed]

40. Funk, S.; Frelat, R.; Möllmann, C.; Krumme, U. The forgotten feeding ground: Patterns in seasonal and depth-specific food intake of adult cod Gadus morhua in the western Baltic Sea. J. Fish Biol. 2021, 98, 3. [CrossRef] [PubMed]

41. Döring, R.; Berkenhagen, J.; Hentsch, S.; Kraus, G. Small-Scale Fisheries in Germany: A Disappearing Profession? In Small-Scale Fisheries in Europe: Status, Resilience and Governance; Pascual-Fernández, J., Pita, C., Bavinck, M., Eds.; MARE Publication Series; Springer: Cham, The Netherlands, 2020; Volume 23. [CrossRef]

42. Mol, A. The Body Multiple. Ontology in Medical Practice; Duke University Press: Durham, NC, USA; p. 216.

43. Ingold, T. The Life of Lines; Routledge: London, UK, 2015; p. 184.

44. Klenk, N. From network to meshwork: Becoming attuned to difference in transdisciplinary environmental research encounters. Environ. Sci. Policy 2018, 89, 315-321. [CrossRef]

45. Barclay, K.; Voyer, M.; Mazur, N.; Payne, A.M.; Mauli, S.; Kinch, J.; Fabinyi, M.; Smith, G. The importance of qualitative social research for effective fisheries management. Fish. Res. 2017, 186, 426-438. [CrossRef]

46. Schreier, M. Content Analysis in Practice; Sage: London, UK, 2012; pp. 171-183.

47. Prior, L. Using Documents in Social Research; Sage: London, UK, 2003; p. 210.

48. Burns, T.R.; Stöhr, C. Power, knowledge, and conflict in the shaping of commons governance. The case of EU Baltic fisheries. ISAC 2011, 5, 233-258. [CrossRef]

49. Long, R. The Role of Regional Advisory Councils in the European Common Fisheries Policy: Legal Constraints and Future Options. Int. J. Mar. Coast. Law 2009, 25, 289-346. [CrossRef]

50. Linke, S.; Jentoft, S. Ideals, realities and paradoxes of stakeholder participation in EU fisheries governance. Environ. Sociol. 2016, 2, 144-154. [CrossRef]

51. ICES. Baltic Fisheries Assessment Working Group (WGBFAS); ICES Scientific Reports; ICES: Copenhagen, Denmark, 2019. [CrossRef]

52. King, N.; Horrocks, C.; Brooks, J. Interviews in Qualitative Research, 2nd ed.; Sage: London, UK, 2018 ; p. 360.

53. Suri, H. Purposeful Sampling in Qualitative Research Synthesis. Qual. Res. J. 2011, 11, 63-75. [CrossRef]

54. Palinkas, L.A.; Horwitz, S.M.; Green, C.A.; Wisdom, J.P.; Duan, N.; Hoagwood, K. Purposeful sampling for qualitative data collection and analysis in mixed method implementation research. Adm. Policy Ment. Health 2015, 42, 533-544. [CrossRef]

55. Herzog, H. On Home Turf: Interview Location and its Social Meaning. In Qualitative Sociology, 2nd ed.; Gubrium, J.F., Holstein, J.A., Marvasti, A.B., McKinney, K.D., Eds.; Sage: London, UK, 2005; Volume 28, pp. 25-47.

56. Cresswell, J.; Cresswell, D. Research Design: Qualitative, Quantitative, and Mixed Methods Approaches, 5th ed.; Sage: London, UK, 2018; p. 304.

57. Stamenova, K.; Hinshelwood, R. (Eds.) Methods of Research into the Unconscious: Applying Psychoanalytical Ideas to Social Science; Routledge: Abington, UK; New York, NY, USA, 2018; p. 282.

58. Charmaz, K. Constructing Grounded Theory; Sage: London, UK, 2006; p. 222.

59. Corbin, J.; Strauss, A. Basics of Qualitative Research: Techniques and Procedures for Developing Grounded Theory, 3rd ed.; Sage: London, UK, 2008; p. 379.

60. Saldana, J. The Coding Manual for Qualitative Researchers, 3rd ed.; Sage: London, UK, 2015; p. 366.

61. Gläser, J.; Laudel, G. Experteninterviews und Qualitative Inhaltsanalyse, 4th ed.; Springer: Wiesbaden, Germany, $2010 ;$ p. 352.

62. EC. Regulation (EU) 2016/1139 of the European Parliament and of the Council of 6 July 2016 Establishing a Multiannual Plan for the Stocks of Cod, Herring and Sprat in the Baltic Sea and the Fisheries Exploiting Those Stocks, Amending Council Regulation (EC) No 2187/2005 and Repealing Council Regulation (EC) No 1098/2007; EC: Brussels, Belgium, 2016.

63. Knight, F.H. Risk, Uncertainty and Profit; Courier Dover Publications: Mineola, NY, USA, 1921.

64. Lempert, R.J.; Collins, M.T. Managing the risk of uncertain threshold responses: Comparison of robust, optimum, and precautionary approaches. Risk Anal. Int. J. 2007, 27, 1009-1026. [CrossRef]

65. Hadjimichael, A.; Reed, P.M.; Quinn, J.D. Navigating deeply uncertain tradeoffs in harvested predator-prey systems. Complexity 2020, 4170453, 18. [CrossRef]

66. Marchau, V.A.; Walker, W.E.; Bloemen, P.J.; Popper, S.W. Decision Making under Deep Uncertainty: From Theory to Practice; Springer: Cham, The Netherlands, 2019; p. 405. 
67. Quinn, J.D.; Reed, P.M.; Keller, K. Direct policy search for robust multi-objective management of deeply uncertain socio-ecological tipping points. Environ. Model. Softw. 2017, 92, 125-141. [CrossRef]

68. Funk, S.; Krumme, U.; Temming, A.; Möllmann, C. Gillnet fishers' knowledge reveals seasonality in depth and habitat use of cod (Gadus morhua) in the Western Baltic Sea. ICES J. Mar. Sci. 2020, 77, 1816-1829. [CrossRef]

69. Pálsson, G. Learning by fishing: Practical engagement and environmental concerns. In Linking Social and Ecological Systems: Management Practices and Social Mechanisms for Building Resilience; Berkes, F., Folke, C., Colding, J., Eds.; Cambridge University Press: Cambridge, MA, USA, 1998; pp. 48-66.

70. Haggan, N.; Neis, B.; Baird, I. Introduction. In Fishers' Knowledge in Fisheries Science and Management; Haggan, N., Neis, B., Baird, I., Eds.; UNESCO: Paris, France, 2007; pp. 14-20.

71. Daw, T.M. How Fishers Count: Engaging with Fishers' Knowledge in Fisheries Science and Management; Newcastle University: Newcastle, UK, 2008.

72. Van Hoof, L.; Kraan, M.; Visser, N.M.; Avoyan, E.; Batsleer, J.; Trapman, B. Muddying the waters of the Landing Obligation: How Multi-level governance structures can obscure policy implementation. In The European Landing Obligation. Reducing Discards in Complex, Multi-Species and Multi-Jurisdictional Fisheries; Uhlmann, S.S., Ulrich, C., Kennelly, S.J., Eds.; Springer: Berlin/Heidelberg, Germany, 2019; pp. 179-196. [CrossRef]

73. Folke, C. Traditional knowledge in social-ecological systems. Ecol. Soc. 2004, 9, 7. [CrossRef]

74. Reed, M.S. Stakeholder participation for environmental management: A literature review. Biol. Conserv. 2008, 141, $2417-2431$. [CrossRef]

75. Steins, N.; Kraan, M.L.; van der Reijden, K.J.; Quirijns, F.J.; van Broekhoven, W.; Poos, J.J. Integrating collaborative research in marine science: Recommendations from an evaluation of evolving science-industry partnerships in Dutch demersal fisheries. Fish Fish. 2019, 21, 146-161. [CrossRef]

76. Arnstein, S.R. A ladder of citizen participation. J. Am. Plan. Assoc. 1969, 35, 216-224. [CrossRef]

77. Degnbol, D.; Wilson, D.C. Spatial planning on the North Sea: A case of cross-scale linkages. Mar. Policy 2008, 32, 189-200. [CrossRef]

78. Linke, S.; Bruckmeier, K. Co-management in fisheries-Experiences and changing approaches in Europe. Ocean Coast. Manag. 2015, 104, 170-181. [CrossRef]

79. Miret-Pastor, L.; Svels, K.; Freeman, R. Towards territorial development in fisheries areas: A typology of projects funded by Fisheries Local Action Groups. Mar. Policy 2020, 119, 104111. [CrossRef]

80. EC. FARNET. Fisheries Areas Network. 2021. Available online: https://webgate.ec.europa.eu/fpfis/cms/farnet2/node_en (accessed on 12 July 2021).

81. Linke, S.; Dreyer, M.; Sellke, P. The Regional Advisory Councils. What is their potential to incorporate stakeholder knowledge into fisheries governance? AMBIO 2011, 40, 133-143. [CrossRef] [PubMed]

82. Linke, S.; Jentoft, S. Exploring the phronetic dimension of stakeholders' knowledge in EU fisheries governance. Mar. Policy 2014, 47, 153-161. [CrossRef]

83. Wenger, E. Communities of Practice. Learning, Meaning, and Identity; Cambridge University Press: Cambridge, MA, USA, 1998; p. 336.

84. Lupp, G.; Zingraff-Hamed, A.; Huang, J.J.; Oen, A.; Pauleit, S. Living Labs-A Concept for Co-Designing Nature-Based Solutions. Sustainability 2021, 13, 3012. [CrossRef]

85. Long, R.; Charles, A.; Stephenson, R.L. Key principles of ecosystem-based management: The fishermen's perspective. Fish Fish. 2015, 18, 244-253. [CrossRef]

86. Levin, P.; Breslow, S.J.; Harvey, C.J.; Norman, K.; Poe, M.; Williams, G.D.; Plummer, M.L. Conceptualization of Social-Ecological Systems of the California Current: An Examination of Interdisciplinary Science Supporting Ecosystem-Based Management. Coast. Manag. 2016, 44, 1-12. [CrossRef]

87. Piet, G.; Delacámara, G.; Kraan, M.; Röckmann, C.; Lago, M. Advancing Aquatic Ecosystem-Based Management with Full Consideration of the Social-Ecological System. In Ecosystem-Based Management, Ecosystem Services and Aquatic Biodiversity. Theory, Tools and Applications; O'Higgins, T.G., Lago, M., DeWitt, T.H., Eds.; Springer: Berlin/Heidelberg, Germany, 2020.

88. EC. Regulation (EU) No 1380/2013 of the European Parliament and of the Council of 11 December 2013 on the Common Fisheries Policy, Amending Council Regulations (EC) No 1954/2003 and (EC) No 1224/2009 and Repealing Council Regulations (EC) No 2371/2002 and (EC) No 639/2004 and Council Decision 2004/585/EC; EC: Brussels, Belgium, 2013. 